Network Working Group

Request for Comments: 1480

Obsoletes: 1386
A. Cooper

J. Postel

June 1993

The US Domain

Status of this Memo

This memo provides information for the Internet community. It does not specify an Internet standard. Distribution of this memo is unlimited.

Table of Contents

1. Introduction .......................... 2

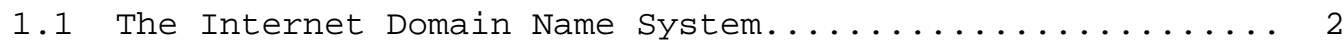

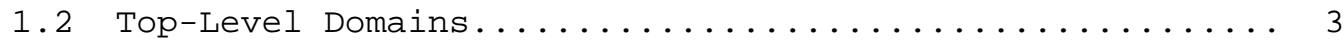

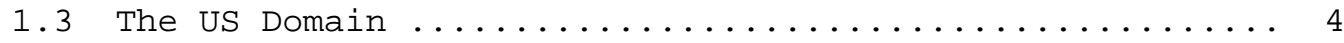

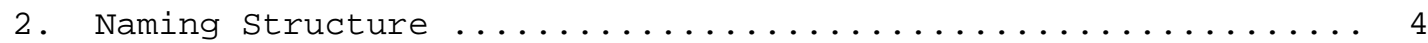

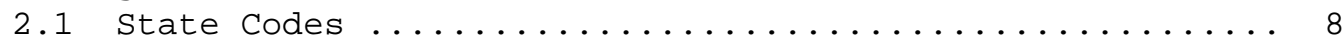

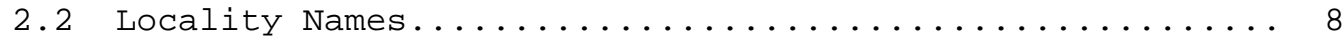

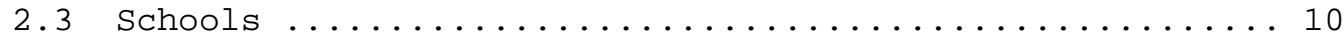

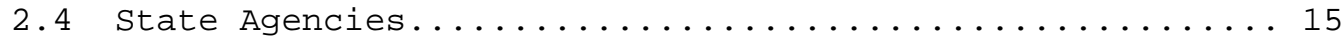

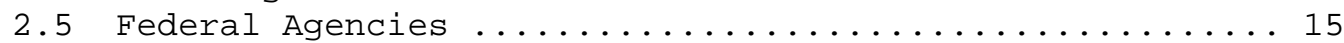

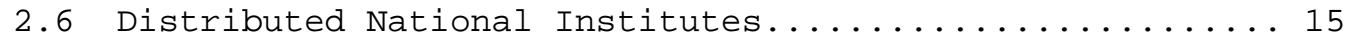

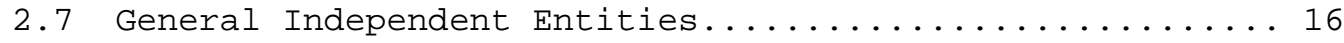

2.8 Examples of Names....................... 17

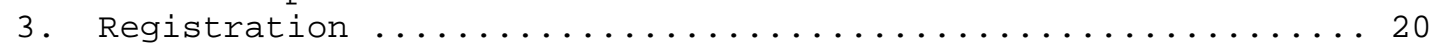

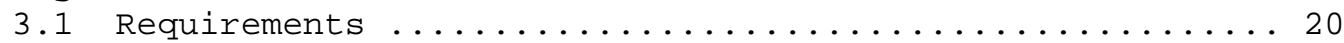

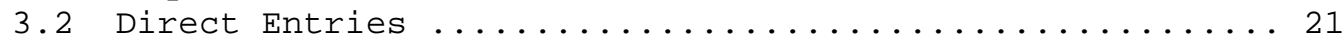

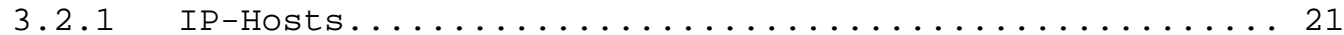

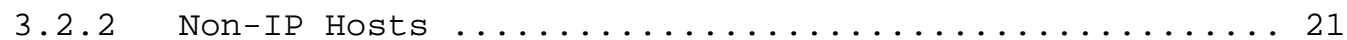

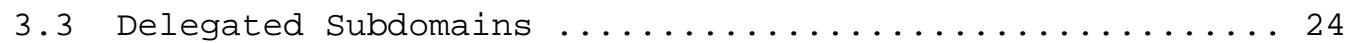

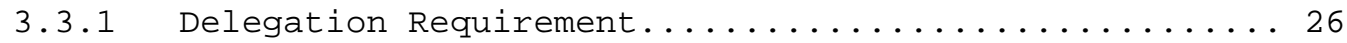

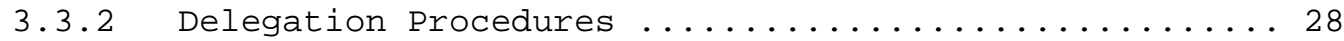

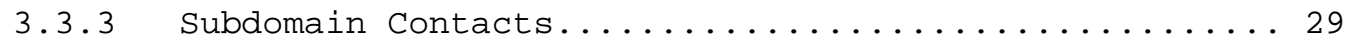

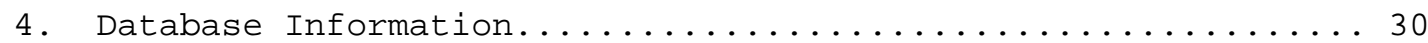

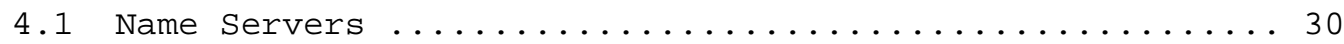

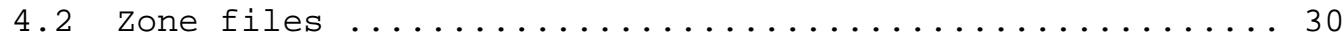

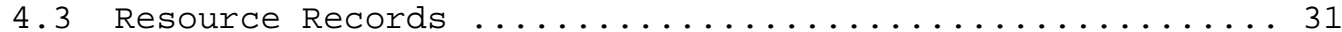

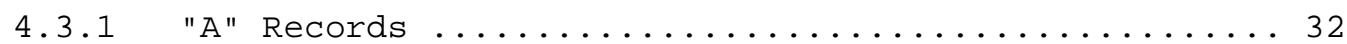

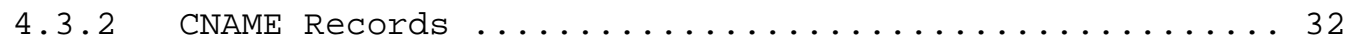

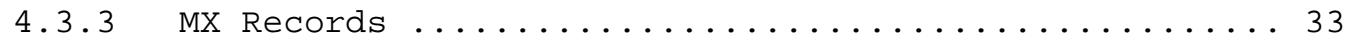

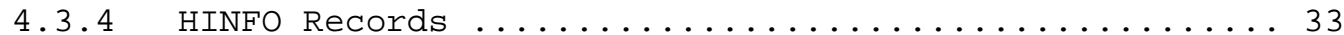

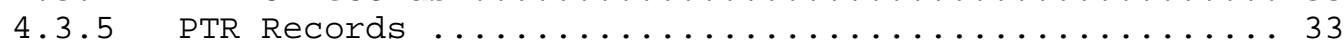

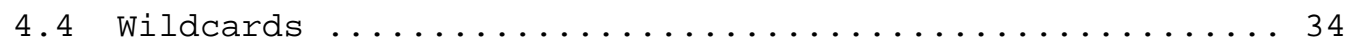

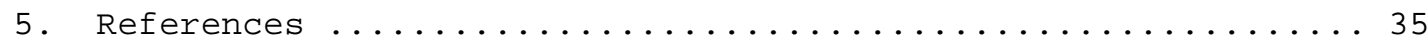




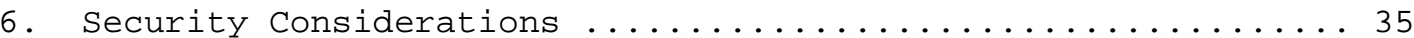

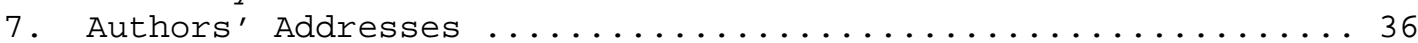

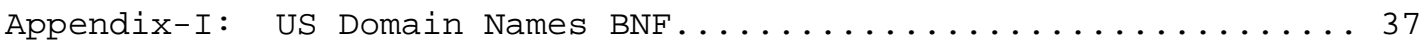

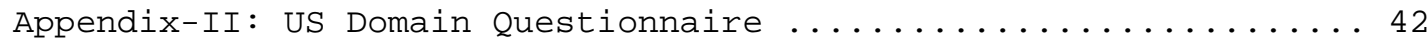

1. INTRODUCTION

\subsection{The Internet Domain Name System}

The Domain Name system (DNS) provides for the translation between hostnames and addresses. Within the Internet, this means translating from a name such as "venera.isi.edu", to an IP address such as "128.9.0.32". The DNS is a set of protocols and databases. The protocols define the syntax and semantics for a query language to ask questions about information located by DNS-style names. The databases are distributed and replicated. There is no dependence on a single central server, and each part of the database is provided in at least two servers.

The assignment of the 32-bit IP addresses is a separate activity. IP addresses are delegated by the central Internet Registry to regional authorities (such as the RIPE NCC for Europe) and the network providers.

To have a network number assigned please contact your network service provider or regional registration authority. To determine who this is (or as a last resort), you can contact the central Internet Registry at Hostmaster@INTERNIC.NET.

In addition to translating names to addresses for hosts that are on the Internet, the DNS provides for registering DNS-style names for other hosts reachable (via electronic mail) through gateways or mail relays. The records for such name registrations point to an Internet host (one with an IP address) that acts as a mail forwarder for the registered host. For example, the host "bah.rochester.ny.us" is registered in the DNS with a pointer to the mail relay "relayl.uu.net". This type of pointer is called an MX record.

This gives electronic mail users a uniform mail addressing syntax and avoids making users aware of the underlying network boundaries.

The reason for the development of the domain system was growth in the Internet. The hostname to address mappings were maintained by the InterNIC in a single file, called HOSTS.TXT, which was FTP'd by all the hosts on the Internet. The network population was changing in character. The time-share hosts that made up the original ARPANET were being replaced with local networks of workstations. Local organizations were administering their own names and addresses, but 
had to wait for the NIC to make changes in HOSTS.TXT to make the changes visible to the Internet at large. Organizations also wanted some local structure on the name space. The applications on the Internet were getting more sophisticated and creating a need for general purpose name service. The idea of a hierarchical name space, with the hierarchy roughly corresponding to organizational structure, and names using "." as the character to mark the boundary between hierarchy levels was developed. A design using a distributed database and generalized resources was implemented.

The DNS provides standard formats for resource data, standard methods for querying the database, and standard methods for name servers to refresh local data from other name servers.

\subsection{Top-Level Domains}

The top-level domains in the DNS are EDU, COM, GOV, MIL, ORG, INT, and NET, and all the 2-letter country codes from the list of countries in ISO-3166. The establishment of new top-level domains is managed by the Internet Assigned Numbers Authority (IANA). The IANA may be contacted at IANA@ISI.EDU.

Even though the original intention was that any educational institution anywhere in the world could be registered under the EDU domain, in practice, it has turned out with few exceptions, only those in the United States have registered under EDU, similarly with COM (for commercial). In other countries, everything is registered under the 2-letter country code, often with some subdivision. For example, in Korea (KR) the second level names are AC for academic community, CO for commercial, GO for government, and RE for research. However, each country may go its own way about organizing its domain, and many have.

There are no current plans of putting all of the organizational domains EDU, GOV, COM, etc., under US. These name tokens are not used in the US Domain to avoid confusion.

Currently, only four year colleges and universities are being registered in the EDU domain. All other schools are being registered in the US Domain.

There are also concerns about the size of the other top-level domains (especially COM) and ideas are being considered for restructuring.

Other names sometimes appear as top-level domain names. Some people have made up names in the DNS-style without coordinating or registering with the DNS management. Some names that typically appear are BITNET, UUCP, and two-letter codes for continents, such as 
"NA" for North America (this conflicts with the official Internet code for Namibia).

For example, the DNS-style name "KA7EEJ.CO.USA.NA" is used in the amateur radio network. These addresses are never supposed to show up on the Internet but they do occasionally. The amateur radio network people created their own naming scheme, and it interferes sometimes with Internet addresses.

\subsection{The US Domain}

The US Domain is an official top-level domain in the DNS of the Internet community. The domain administrators are Jon Postel and Ann Westine Cooper at the Information Sciences Institute of the University of Southern California (USC-ISI).

US is the ISO-3166 2-letter country code for the United States and thus the US Domain is established as a top-level domain and registered with the InterNIC the same way other country domains are.

Because organizations in the United States have registered primarily in the EDU and COM domains, little use was initially made of the US domain. In the past, the computers registered in the US Domain were primarily owned by small companies or individuals with computers at home. However, the US Domain has grown and currently registers hosts in federal government agencies, state government agencies, K12 schools, community colleges, technical/vocational schools, private schools, libraries, city and county government agencies, to name a few.

Initially, the administration of the US Domain was managed solely by the Domain Registrar. However, due to the increase in registrations, administration of subdomains is being delegated to others.

Any computer in the United States may be registered in the US Domain.

\section{NAMING STRUCTURE}

The US Domain hierarchy is based on political geography. The basic name space under US is the state name space, then the "locality" name space, (like a city, or county) then organization or computer name and so on.

For example:

BERKELEY.CA.US

PORTLAND. WA. US 
There is of course no problem with running out of names.

The things that are named are individual computers.

If you register now in one city and then move, the database can be updated with a new name in your new city, and a pointer can be set up from your old name to your new name. This type of pointer is called a CNAME record.

The use of unregistered names is not effective and causes problems for other users. Inventing your own name and using it without registering is not a good idea.

In addition to strictly geographically names, some special names are used, such as FED, STATE, AGENCY, DISTRICT, K12, LIB, CC, CITY, and COUNTY. Several new name spaces have been created, DNI, GEN, and TEC, and a minor change under the "locality" name space was made to the existing CITY and COUNTY subdomains by abbreviating them to CI and $\mathrm{CO}$. A detailed description follows.

Below US, Parallel to states:

"FED" - This branch may be used for agencies of the federal government. For example: <org-name>.<city>.FED.US

"DNI" - DISTRIBUTED NATIONAL INSTITUTES - The "DNI" branch was created directly under the top-level US. This branch is to be used for distributed national institutes; organizations that span state, regional, and other organizational boundaries; that are national in scope, and have distributed facilities. For example:

<org-name>.DNI.US.

Name Space Within States:

"locality" - cities, counties, parishes, and townships. Subdomains under the "locality" would be like CI.<city>.<state>.US, Co.<county>.<state>.US, or businesses. For example:

Petville.Marvista.CA.US.

"CI" - This branch is used for city government agencies and is a subdomain under the "locality" name (like Los Angeles). For example: Fire-Dept.CI.Los-Angeles.CA.US.

"CO" - This branch is used for county government agencies and is a subdomain under the "locality" name (like Los Angeles). For example: Fire-Dept.CO.San-Diego.CA.US. 
"K12" - This branch may be used for public school districts. A special name "PVT" can be used in the place of a school district name for private schools. For example: <school-name>.K12.<state>. US and <school-name>.PVT.K12.<state>.US.

"CC" - COMMUNity COLLEgES - This branch was established for all state wide community colleges. For example: <school-name>.CC.<state>. US.

"TEC" - TECHNICAL AND VOCATIONAL SCHOOLS - The branch "TEC" was established for technical and vocational schools and colleges. For example: <school-name>.TEC.<state>.US.

"LIB" - LIBRARIES (STATE, REGIONAL, CITY, COUNTY) - This branch may be used for libraries only. For example: <lib-name>.LIB.<state>. US.

"STATE" - This branch may be used for state government agencies. For example: <org-name>.STATE.<state>.US.

"GEN" - GENERAL INDEPENDENT ENTITY - This branch is for the things that don't fit easily into any other structure listed -- things that might fit in to something like ORG at the top-level. It is best not to use the same keywords (ORG, EDU, COM, etc.) that are used at the top-level to avoid confusion. GEN would be used for such things as, state-wide organizations, clubs, or domain parks. For example: <org-name>. GEN. <state-code>.US.

$++++++++++++++++++++++++++++++++++++++++++++++++++++++++++++++++++++$

VIEW OF SECOND LEVEL DOMAINS UNDER US

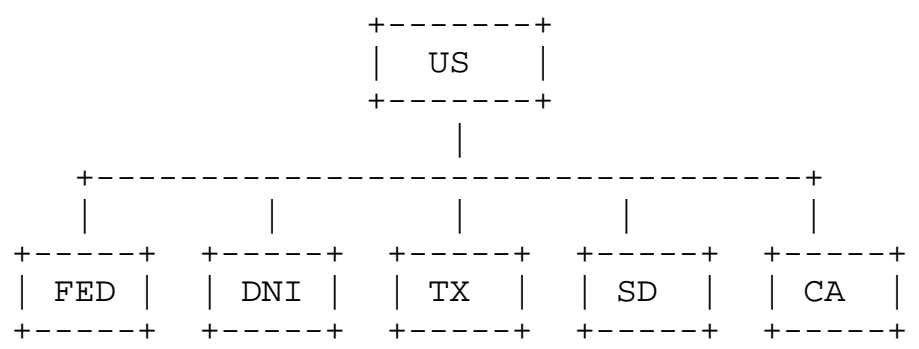

$++++++++++++++++++++++++++++++++++++++++++++++++++++++++++++++++++++$ 


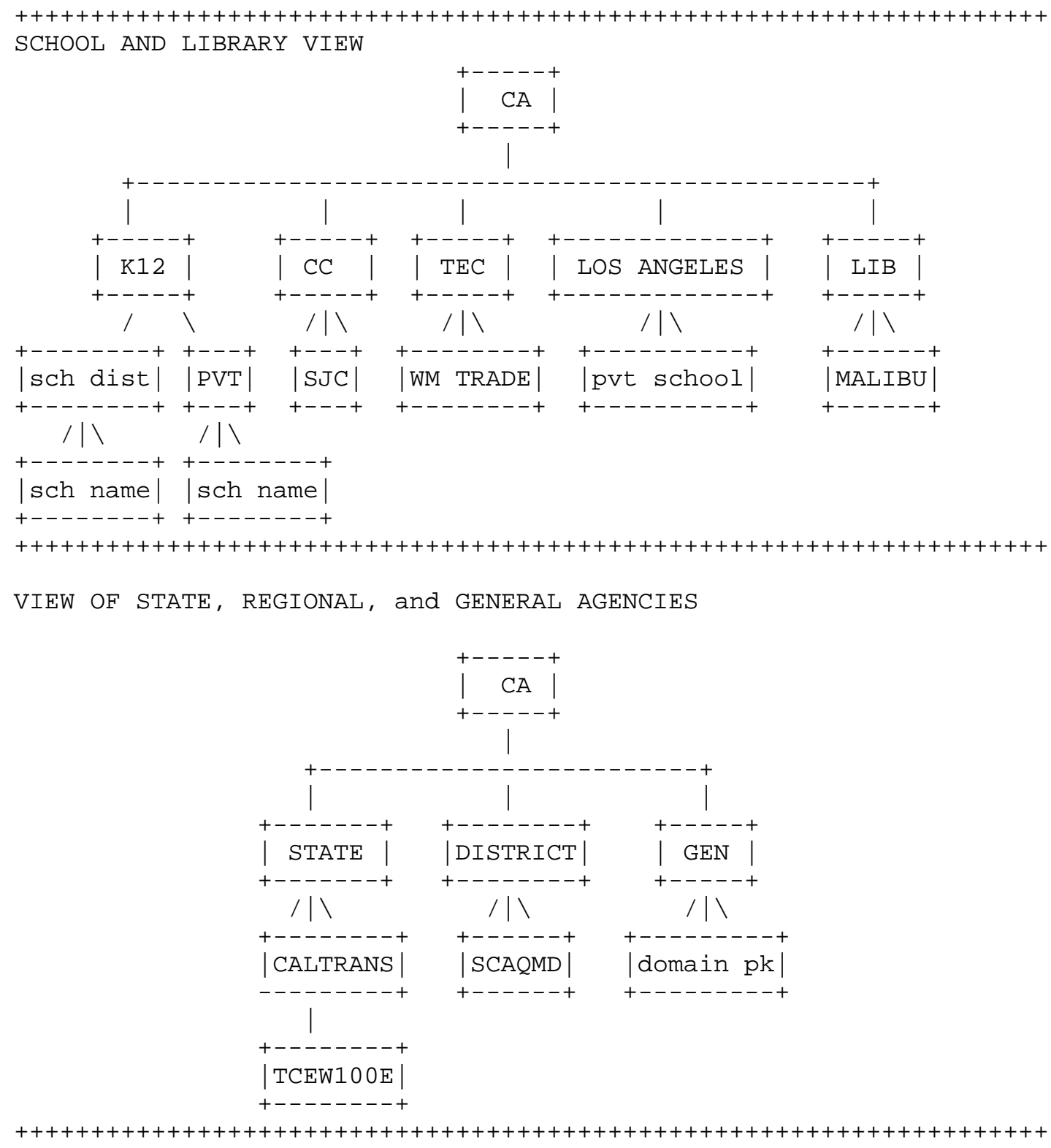




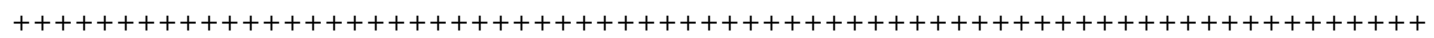

VIEW OF LOCALITY

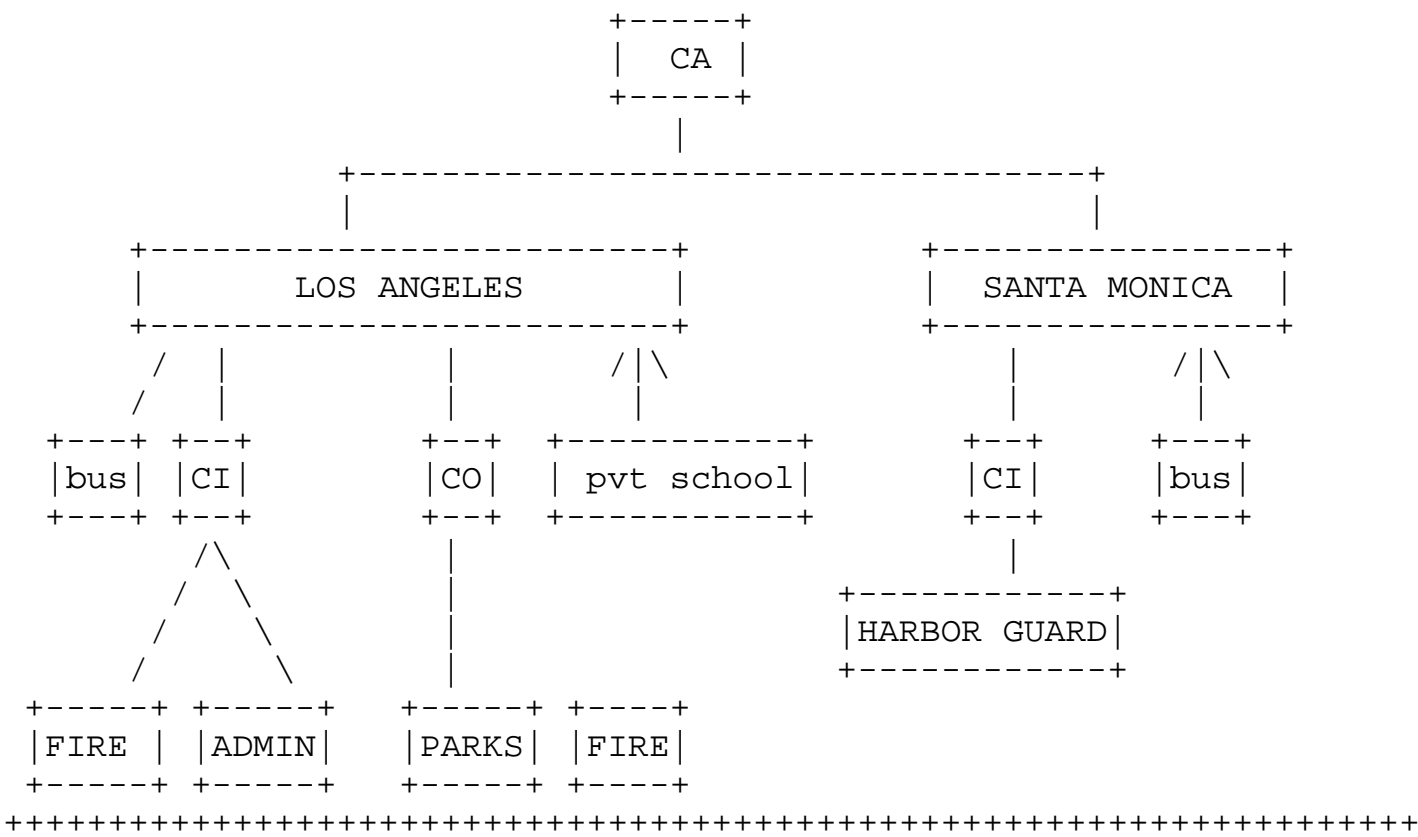

\subsection{State Codes}

The state codes are the two letter US Postal abbreviations. For example: "CA" California.

\subsection{Locality Names}

Within the state name space there are "locality" names, some may be cities, some may be counties, some may be local names, but not incorporated entities.

Registered names under "locality" could be like:

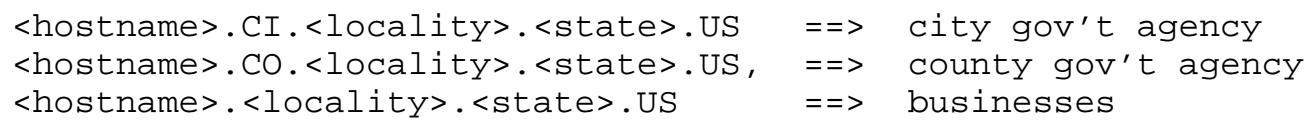

In the cases where the locality name is a county, there is a branch under the locality name, called "county" or "Co", that is used by the county government. Businesses are registered directly under the locality name. 
Under the city locality name space there is a "city" or "CI" branch for city government agencies. As usual, businesses and private schools may register directly under the city name.

In the case where there is both a county and a city with the same locality name there is no problem, since the names will be unique with the "CO" or "CI" keyword. In our area the county has a fire department and the city has its own fire department. They could have names like:

Fire-Dept.CI.Los-Angeles.CA.US

Fire-Dept.CO.Los-Angeles.CA.US

Cities may be named (designated) by their full name (spelled out with hyphens replacing spaces (e.g., Los-Angeles or Fort-Collins), or by a city code. The first choice is the full city name. In some cases it may be appropriate to use the well-known city abbreviation known throughout a locality. However, it is very desirable that all users in the same city use the same designator for the city. That is, any particular locality should have just one DNS name.

Some users would like names associated with a greater metropolitan area or region like the "Bay Area" or "Tri-Cities". One problem with this is that these names are not necessarily unique within a state. The best thing to do in this case is to use the larger metropolitan city in your hostname. Cities and counties are used.

Should all the names be obvious? Trying to do this is desirable and also impossible. There will come a point when the obviously right name for an organization is already taken. As the system grows this will happen with increasing frequency. While ease of use to the end user is desirable, a higher priority must be placed on having a system that operates. This means that the manageability of the system must have high consideration.

The reason the DNS was created was to subdivide the problem of maintaining a list of hosts in the Internet into manageable portions.

The happy result is that this subdivision makes name uniqueness easier and promotes logical grouping. What is a "logical grouping" though, always depends on the viewer.

Many levels of delegation are needed to keep the zone files manageable. Many sections of the name space are needed to allow unique names to be easily added. 
Way back in the olden days, when the Internet was invented, some thought that an 8-bit network number would be more than enough to number all the networks that would ever exist. Today, there are over 10,000 networks operating in the Internet, and arguments are made about the doubling time being 2 years versus 4 years.

One concern is that things will continue to grow dramatically, and this will require more subdivision of the domain name management. Maybe the plan for the US Domain is overkill on growth planning, but there has never been overplanning for growth yet.

When things are bigger, names have to be longer. There is an argument that with only 8-character names, and in each position allow $a-z, 0-9$, and - , you get $37 * \star 8=3,512,479,453,921$ or 3.5 trillion possible names. It is a great argument, but how many of us want names like "xs4gp-7q". It is like license plate numbers, sure some people get the name they want on a vanity plate, but a lot more people who want something specific on a vanity plate can't get it because someone else got it first. Structure and longer names also let more people get their "obviously right" name.

\subsection{Schools}

K12 schools are connecting to the Internet and registering in the Internet DNS. A decision has been made by the IANA (after consultation with the new InterNIC Internet Registry and the Federal Networking Council (FNC)) to direct these school registrations to the US domain using the naming structure described here.

There is a need for competent, experienced, volunteers to come forward to act as third and perhaps fourth level registries and to operate delegated portions of the DNS.

There are two reasons for registering schools in the US Domain. uniqueness of names, and (2) management of the database.

1. Name Uniqueness:

There are many "Washington" high schools, only one can be "Washington.EDU" (actually none can be, since that name is used by a University. There will be many name conflicts if all schools attempt to register directly under EDU.

In addition, in some districts, the same school name is used at different levels, for example, Washington Elementary school and Washington High School. We suggest that when necessary, the keywords "Elementary", "Middle", and "High" be used to distinguish these schools. These keywords would only be used 
when they are needed, if the school's name is unique without such keywords, don't use them.

2. Database Management:

One goal of the DNS is to divide up the management of the name database in to small pieces. Each piece (or "zone" in DNS terminology) could be managed by a distinct administrator. Adding all the high schools to the EDU domain will make the already large zone file for EDU even larger, possibly to the point of being unmanageable.

For both these reasons it is necessary to introduce structure into names. Structure provides a basis for making common names unique in context, and for dividing the management responsibility.

The US Domain has a framework established and has registered many schools already in this structured scheme. The general form is:

<school>.<district>.K12.<state>.US.

For example: Hamilton.LA-Unified.K12.CA.US

Public schools are usually organized by districts which can be larger or smaller than a city or county. For example, the portland school district in Oregon, is in three or four counties. Each of those counties also has non-Portland districts.

It makes sense to name schools within districts. However districts often have the same name as a city or county so there has to be a way to distinguish a public school district name from some other type of locality name. The keyword "K12" is used for this.

For example, typical K12 school names currently used are:

IVY.PRS.K12.NJ.US

DMHS.JCP S.K12.KY.US

OHS.EUNION.K12.CA.US

BOHS.BREA.K12. CA. US

These names are generally longer than the old alternative of shorter names in the EDU domain, but that would not have lasted long without a significant number of schools finding that their "obviously correct" name has already been used by some other school. 
When there are many things to name some of the names will be long. In some cases there may be appropriate abbreviations that can be used. For example Hamilton High School in Los Angeles could be:

Hami.Hi.LA.K12.CA.US

If a school has a number of PCs, then each PC should have a name. Suppose they are named "alpha", "beta", ... then if they belong to a school named "Lincoln.High.Lakewood.K12. CA. US" their names would be:

alpha. Lincoln.High. Lakewood.K12.CA.US. beta. Lincoln.High. Lakewood.K12.CA.US

...

The K12 subdomain provides two points at which to delegate a branch of the database to distinct administrators -- the K12 Administrator for each state, and the district administrator for each district within a state.

The US Domain Administrator will delegate a branch of the US domain to an appropriate party. In some cases, this may be a particular school, a school district, or ever all of k12 for a state.

The responsibility for managing a K12 branch or sub-branch may be delegated to an appropriate volunteer. We envision that such delegations of the schools' DNS service may eventually migrate to someone else "more appropriate" from an administrative organizational point of view. The "obvious" state agency to manage the schools' DNS branch may take some time to get up to speed on Internetting. In the meantime, we can have the more advanced schools up and running.

Special Schools and Service Units

In many states, there are special schools that are not in districts that are run directly by the state or by consortiums. There are also service units that provide "educational services" ranging from books and computers to janitorial supplies and building maintenance. Often these service units do not have a one-to-one relationship with districts.

There is some concern about naming these schools and service units within the naming structure for schools established in this memo. There are several possibilities. For a state with many service units creating a "pseudo district" ESU (or whatever, the common terminology is in that state) is a possibility. For example, the Johnson service unit could be JOHNSON.ESU.K12. CA.US. For a state with a few such service units (and avoiding conflicts with district names) the service units could be directly under K12. For example, 
TIES.K12.MN.US .

The special public funded schools can be handled in a similar fashion. If there are many special schools in a state, a "pseudo district" should be established and all the special schools listed under it. For example, suppose there is a "pseudo district" in Massachusetts called SPCL, and there is a special school called the Progressive Computer Institute, then that school could have the name PCI.SPCL.K12.MA.US. If there are only a few special schools, they can be listed directly under K12 (avoiding name conflicts with district names). For example, the California Academy of Math and Science is CAMS.K12.CA.US. CAMS is sponsored by seven schools, the California Department of Education, and a University.

"PVT" Private Schools

Private schools may be thought of as businesses. Public schools are in districts, and districts provide a natural organizational structure for naming and delegation. For private schools there are no districts and they really do operate like businesses. But, many people are upset to think about their children in a private school being in a business category and not in K12 with the rest of the children. To accommodate both public and private schools, in each state's K12 branch, we've added an artificial district called private or "PVT". This gives a private school the option of registering like a business under "locality" or in the PVT.K12.<state-code>. Us branch.

For example:

Crossroads.PVT.K12.CA.US

Crossroads-Santa-Monica.CA.US

A public school "Oak High" in the "Woodward" school district in California would have a name like "Oak-High. Woodward.K12. CA. US".

A private school "Old Trail" in Pasadena, California could have the <locality> based name "Old-Trail.Pasadena.CA.US" or the private school base name "Old-Trail.PVT.K12.CA.US".

Some suggest that for private schools instead of a special pseudo district PVT to use a locality name. One reason to use district names is that, in time, it seems likely that school district administrators will take over the operation of the DNS for their district. One needs to be able to delegate at that branch point. One implication of delegation is that the delegatee is now in charge of a chunk of the name space and will be registering new names. To keep names unique one can't have two different people registering new things below identically named branches. 
For example, if there is a school district named Pasadena and a city named Pasadena, the branch of the name space PASADENA.K12.CA.US might be delegated to the administrator of that public school district. If a private school in Pasadena wanted to be registered in the DNS, it would have to get the public school district administrator to do it (perhaps unlikely) or not be in the K12 branch at all (unless there is the PVT pseudo district).

So, if private schools are registered by <school>. <locality>.K12.<state-code>. US and public schools are registered by <school>.<district>.K12.<state-code>. US, there can't be any locality names that are the same as district names or the delegation of these will get very tricky later.

If it is all done by locality names rather than district names, and public and private schools are mixed together, then finding an appropriate party to delegate the locality to may be difficult.

Another suggestion was that private schools be registered directly under K12, while public schools must be under a district under K12. This would require the operator of the K12 branch to register all districts and private schools himself (checking for name uniqueness), he couldn't easily delegate the registration of the private schools to anyone else.

Community Colleges and Technical Schools

To distinguish Community Colleges and Technical/Vocational schools, the keywords "CC" and "TEC" have been created.

Some School Examples

Hamilton.High. LA-Unified.K12.CA.US Sherman-Oaks.Elem.LA-Unified.K12.CA.US

John-Muir.Middle.Santa-Monica.K12.CA.US Crossroads-School. Santa-Monica.CA.US SMCC.CC.CA.US TECMCC.CC.CA.US

Brick-and-Basket-Institute.TEC.CA.US Northridge.CSU.STATE.CA.US

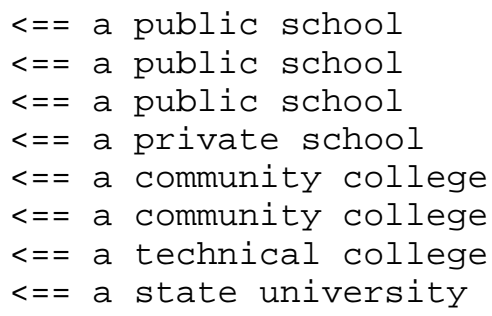




\subsection{State Agencies}

Several states are setting up networks to interconnect the offices of state government agencies. The hosts in such networks should be registered under the STATE.<state-code>. US branch.

A US Domain name space has been established for the state government agencies. For example, in the state of Minnesota, the subdomain is STATE.MN.US.

State Agencies:

\author{
Senate.STATE.MN.US \\ MDH.STATE.MN.US \\ CALTRANS. STATE.CA.US \\ DMV.STATE.CA.US
}

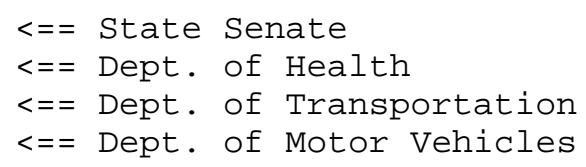

\subsection{Federal Agencies}

A federal name space has been established for the federal government agencies. For example, the subdomain for the Federal Reserve Bank of Minneapolis is MNPL.FRB.FED.US. Other examples are listed below.

Federal Government Agencies:

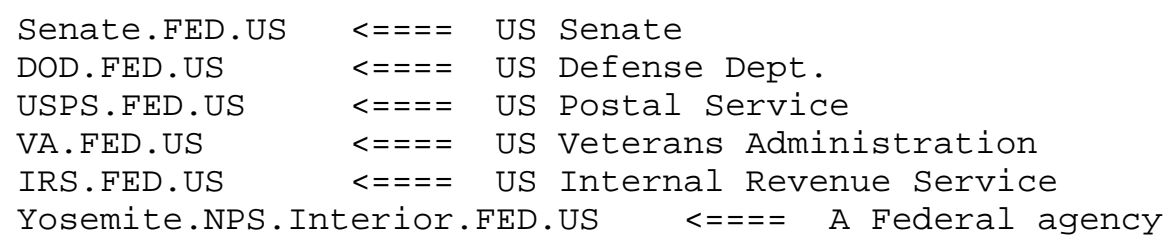

\subsection{Distributed National Institutes}

The "DNI" branch was created directly under the top-level Us. This is to be used for organizations that span state, regional, and other organizational boundaries; are national in scope, and have distributed facilities. An example would be:

Distributed National Institutes:

MetaCenter.DNI.US $<====$ The MetaCenter Supercomputer Centers 
The MetaCenter domain encompasses the four NSF sponsored supercomputer centers. These are:

San Diego Supercomputer Center (SDSC)

National Center for Supercomputing Applications (NCSA)

Pittsburgh Supercomputing Center (PSC)

Cornell Theory Center (CTC)

The MetaCenter Network will enable applications and services like file systems and archival storage to be operated in a distributed fashion; thus, allowing the resources at the four centers to appear integrated and "seamless" to users of the centers.

\subsection{General Independent Entities}

This name space was created for organizations that don't really fit anywhere else, such as state-wide associations, clubs, and "domain parks". Think of this as the miscellaneous category.

The examples are state-wide clubs. For example, the Garden club of Arizona, might want to be "GARDEN.GEN.AZ.US". Such a club has membership from all over the state and is not associated with any one city (or locality). Another example is "domain parks" that have been established up-to-now as entities in ORG. For example, there is "LONESTAR. ORG", which is a kind of computer club in Texas that has lots of dial-in computers registered. In the US Domain such an entity might have a name like "LONESTAR.GEN.TX.US".

The organizations registered in GEN may typically be non-profit entities. These organizations don't fit in a <locality $>$ and are not a school, library, or state agency. Ordinary businesses are not registered in GEN.

Some suggest that these kinds of organizations are just like all the other things and ought to be registered under some <locality>. This may be true, but sometimes one just can't find any way to convince the applicant that it is the right thing to do. One can argue that any organization has to have a headquarters, or an office, or something about it that is in a fixed place, and thus the organization could be registered in that place.

Some suggest that no token is needed, these entities could be directly under the <state-code>. The problem with not having a token, is that you can't delegate the responsibility for registering these entities to someone separate from whoever is responsible for the <state-code>. You want to be able to delegate for both nameuniqueness reasons, and operational management reasons. Having a token there makes both easy. 
General Independent Entities:

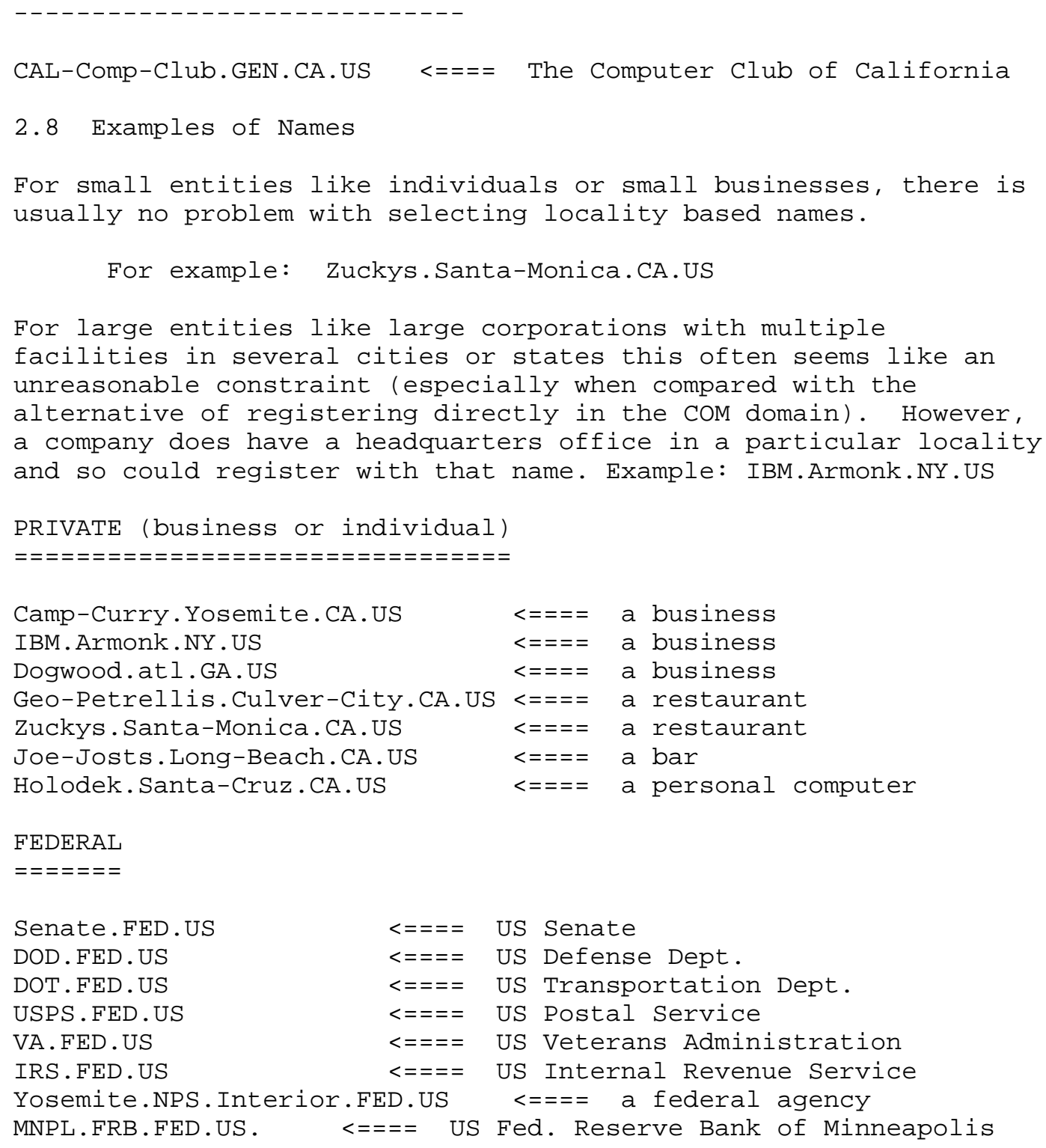


STATE

$====$

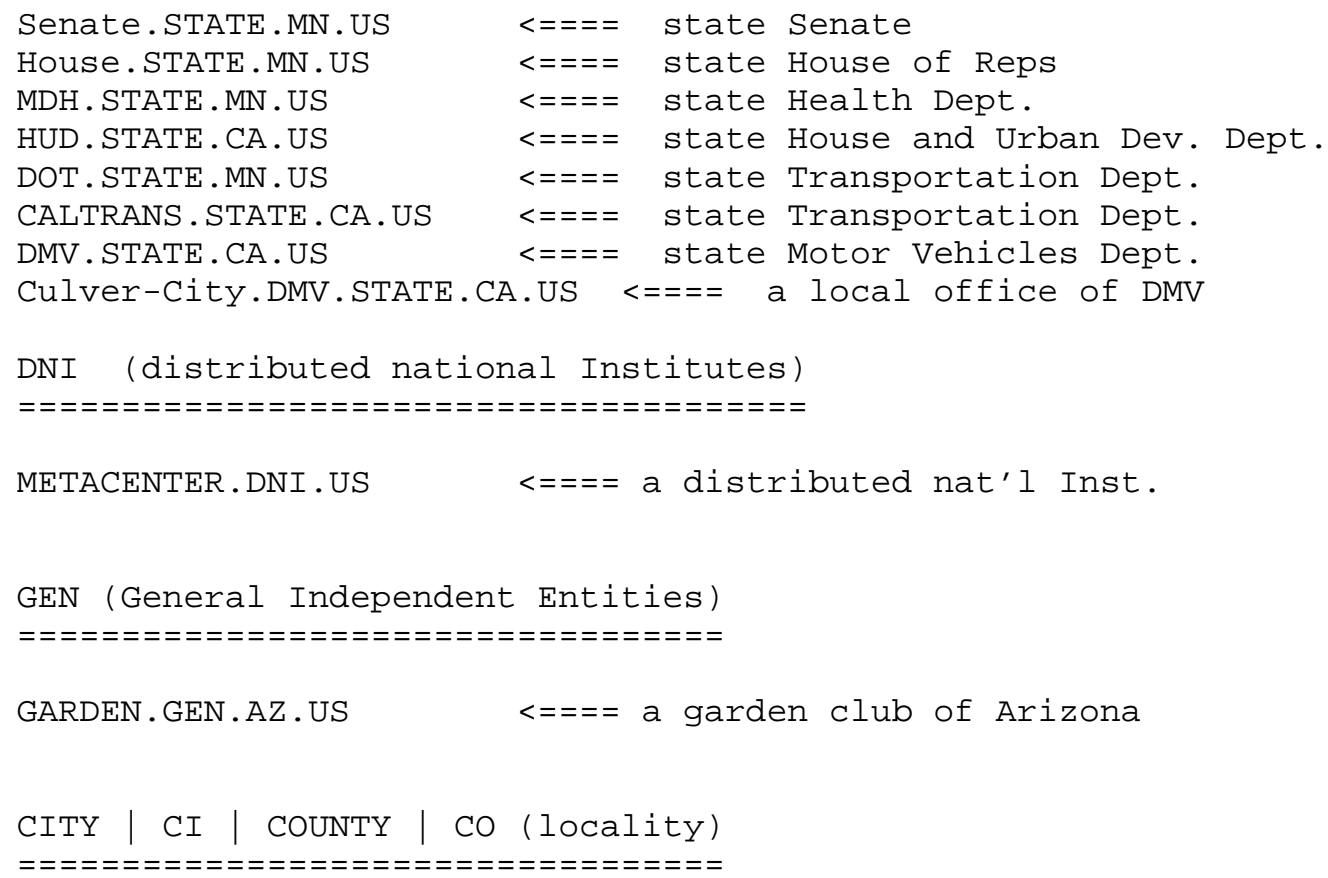




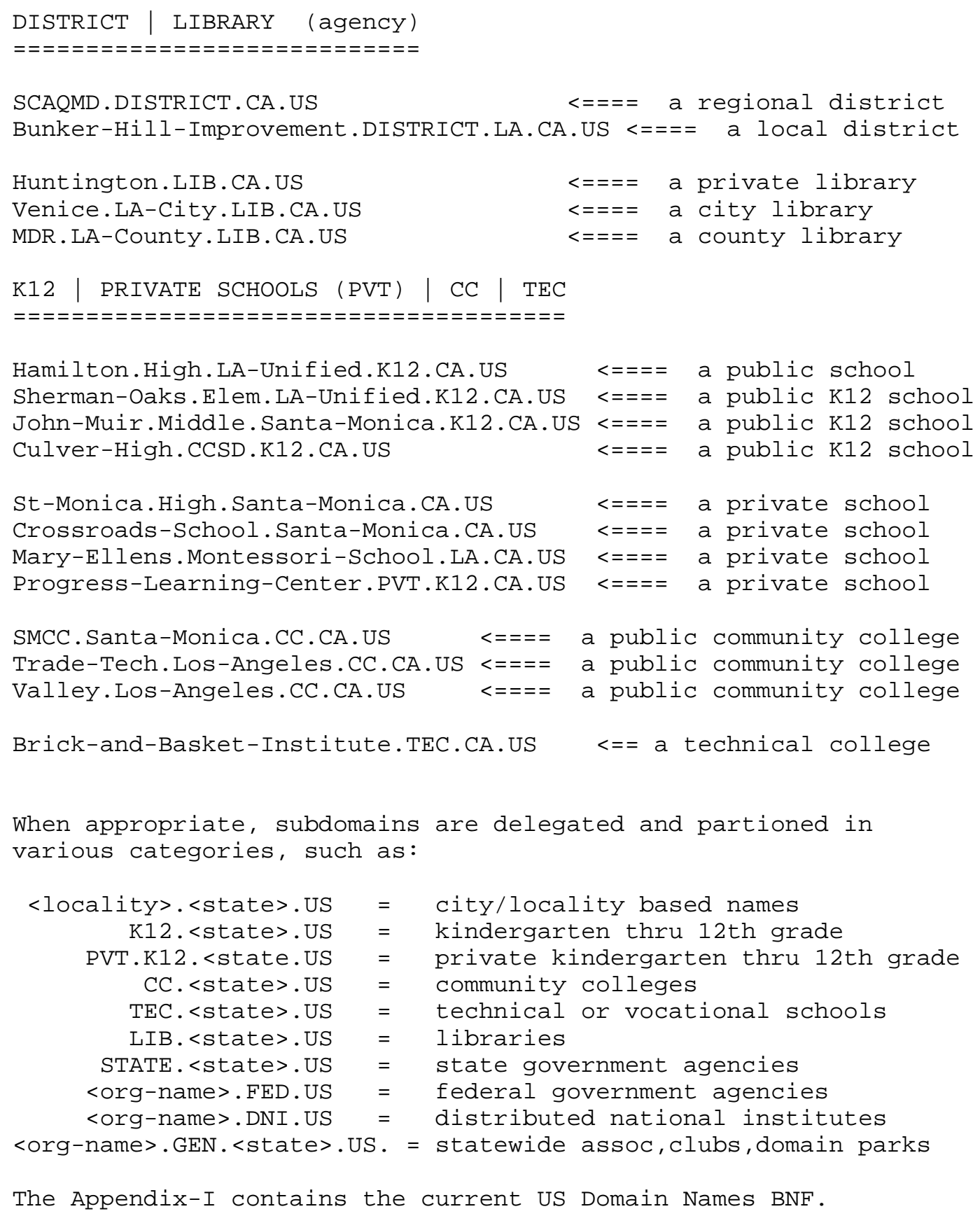




\section{REGISTRATION}

There are two types of registrations (1) Delegation, where a branch of the US Domain is delegated to an organization running name servers to support that branch; or (2) Direct Registration, in which the information is put directly into the main database.

In Direct Registration there are two cases: (a) an IP-host (with an IP address), and (b) non-IP host (for example, a UUCP host). Any particular registration will involve any one of these three situations.

\subsection{Requirements}

Anyone requesting to register a host in the US Domain is sent a copy of the "Instructions for the US Domain Template", and must fill out a US Domain template.

The US Domain template, is similar to the InterNIC Domain template, but it is not the same. To request a copy of the US Domain template, send a message to the US Domain registrar (us-domaineisi.edu).

If you are registering a name in a delegated zone, please register with the contact for that zone. You can FTP the file "in-notes/usdomain-delegated.txt" from venera.isi.edu, via anonymous FTP. This information is also available via email from RFC-INFO@ISI.EDU (include as the only text in the message

"Help: us_domain_delegated_domains") .

The key people must have electronic mailboxes (that work). Please provide all the information indicated in the "Administrator" and "Technical contact" slots.

The administrator will be the point of contact for any administrative and policy questions about the domain. The administrator is usually the person who manages the organization being registered.

The technical contact can also be administrator, or the systems person, or someone who is familiar with the technical details of the Internet. The technical contact should have a valid working email address. This is necessary in case something goes wrong.

It is important that your "Return-Path" and "From" field indicate an Internet-style address. UUCP-style addresses such as "hostl!user" will not work. This is fine within the UUCP world, but not the Internet. If you want people on the Internet to be able to send mail to you, your return path needs to be an Internet-style address such as: host1!user@Internet.gateway.host or user@Internet.gateway.host. 
It is also possible to register through one of the Internet service providers that have established working relationships with the US Domain Administrator.

If everything checks out, the turn around time for registering a host is usually a few days. The name servers are updated anywhere from 12 to 24 hours later.

There are two ways to be registered in the US Domain, directly, or by delegation.

\subsection{Direct Entries}

Direct entry in the database of the US Domain appeals most to individuals and small companies. You may fill out the application and send it directly to the US Domain Administrator. If you are in an area where the zone is delegated to someone else your request will be forwarded to the zone administrator for your registration. Or, you may send the form directly to the manager of a delegated zone (see Section 3.1).

\subsubsection{IP-Hosts}

These are hosts with IP addresses which correspond to "A" records in the DNS database.

\subsubsection{Non-IP Hosts}

Many applicants have hosts in the UUCP world. Some are one hop away, some two and three hops away from their "Internet Forwarder", this is acceptable. What is important is getting an Internet host to be your forwarder. If you do not already have an Internet forwarder, there are several businesses that provide this service for a fee, such as UUNET.UU.NET (postmaster@uunet.uu.net), PSI (postmaster@UU2.PSI.COM) and CERFNET (help@cerf.net). Sometimes local colleges in your area are already on the Internet and may be willing to act as an Internet Forwarder. You would need to work this out with the systems administrator as we cannot make these arrangements for you.

Although we work with UUCP service providers, the Internet US Domain registration is not affiliated with the registration of UUCP Map entries. The UUCP map entry does not provide us with sufficient information. If you do not have a copy of the US Domain questionnaire template, please send a message to: us-domain@isi.edu and request one. See Appendix-II. 
The example below is not an appropriate registration for the US Domain.

\#N starl

\#S Amiga 2500; Amigados 2.04; Dillon's AmigaUUCP 1.15D

\#O Starlight BBS

\#C Stephen Baker

\#E starl!sbaker

$\# \mathrm{~T}+1 \quad 305 \quad 378 \quad 1161$

\#P 1107 SW 200th St \#303B Miami, Fl. 33157

\#L $2547 \mathrm{~N} / 8810 \mathrm{~W}$ [city]

\# $\mathrm{R}$

\#U mthvax

\#W starl!sbaker (Stephen Baker); Mon Feb 24 19:58:24 EST 1992

starl mthvax (DAILY)

If you are registering your host as a central site for a USENET group where other UUCP sites will feed from you, that's fine. These UUCP sites do not need to register. If however, the other sites become a subdomain of your hostname, then we will need to register them

individually or add a wildcard record. (See Section 4.4. Wildcards).

$$
\text { For example: bah.rochester.ny.us }
$$

host 1 .bah.rochester.ny.us

host 2 .bah.rochester.ny.us

To use US Domain names for non-IP hosts, there must be a forwarder host that is an IP host. There must be an administrative agreement and a technical procedure for relaying mail between the non-IP host and the forwarder host.

Case 1:

Your host is not an IP host but does talk directly with a host that is an IP host.

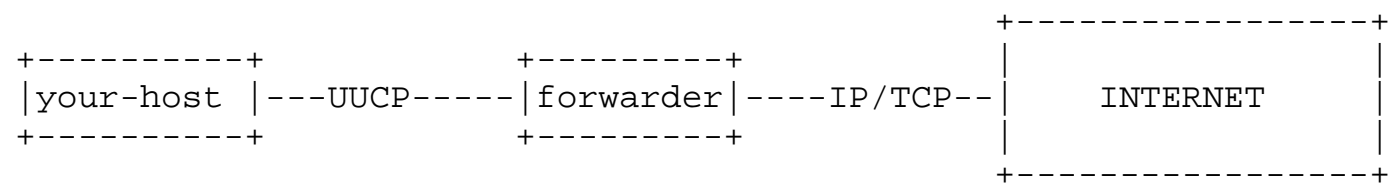

"Forwarder" must be an IP host on the Internet.

You must ask "forwarder" if they are willing to be the Internet forwarder for "your-host".

In the US Domain of the DNS data base there must be an entry like this:

$$
\text { "your-host" MX } 10 \text { "forwarder" }
$$


This must be entered by the US Domain Administrator.

In the "forwarder" routing tables there must be information about "your-host" with a rule like: If I see mail for "your-host" I will send it via uucp by calling phone number "123-4567".

Case 2:

In this case your hosts talks to another host that ... that talks to an IP host. In other words, there are multiple hops between your host and the Internet.

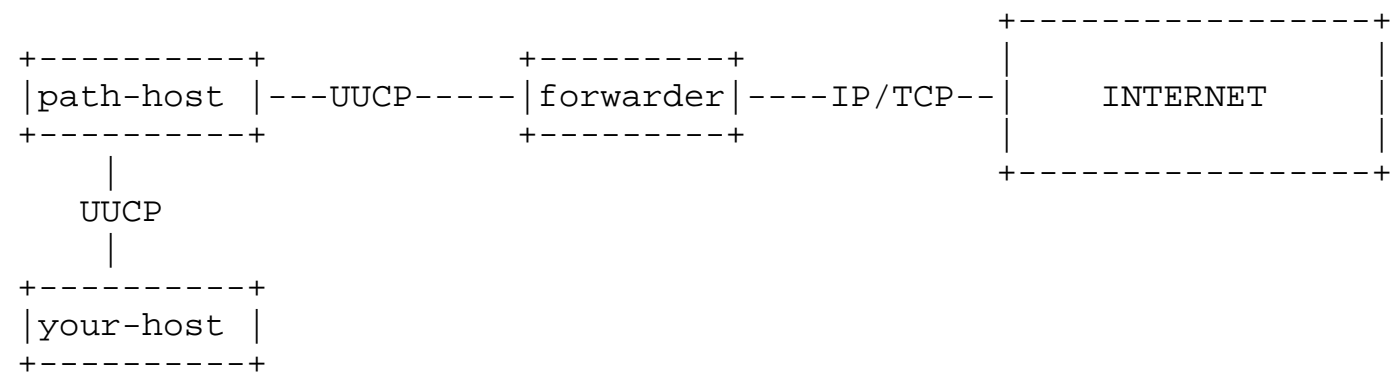

"Forwarder" must be an IP host on the Internet.

You must ask "forwarder" if they are willing to be the Internet Forwarder for "Your-Host". You must ask "path-host" to relay your mail.

In the US Domain of the DNS Database there must be an entry like this: "your-host" MX 10 "forwarder"

This must be entered by the US Domain Administrator.

In the "forwarder" routing tables there must be information about "your-host" with a rule like: If I see mail for "your-host" I will send it via UUCP to "path-host" by calling phone number "123-4567". and "path-host" must also know how to relay the mail to "your-host".

Note: It is assumed that "path-host" is already MXed to "forwarder". It is not appropriate to ask to MX "your-host" to "path-host" (this is sometimes called double MXing). The host on the right hand side of an MX entry must be a host on the Internet with an IP address $(e . g \cdot, 128.9 .2 .32)$. 


\subsection{Delegated Subdomains}

Many branches of the US Domain are delegated. There must be a knowledgeable and competent technical contact, familiar with the Internet DNS. This requirement is easily satisified if the technical contact already runs some other name servers.

Examples of delegations are K12.TX.US for the Kindergarten through 12th Grade public schools in Texas, the locality "berkeley.ca.us", or the LIB.MN.US branch for the libraries in Minnesota.

The administrator of the US Domain is responsible for the assignment of all the DNS names that end with ".US". Of course, one person or even one group can't handle all this in the long run so portions of the name space are delegated to others.

The major concern in selecting a designated manager for a domain is that it be able to carry out the necessary responsibilities, and have the ability to do an equitable, just, honest, and competent job.

The key requirement is that for each domain there be a designated manager for supervising that domain's name space.

These designated authorities are trustees for the delegated domain, and have a duty to serve the community.

The designated manager is the trustee of the domain for the domain itself and the global Internet community.

Concerns about "rights" and "ownership" of domains are inappropriate. It is appropriate to be concerned about "responsibilities" and "service" to the community.

The designated manager must be equitable to all groups in the domain that request domain names.

This means that the same rules are applied to all requests. All requests must be processed in a nondiscriminatory fashion, and academic and commercial (and other) users are treated on an equal basis. No bias shall be shown regarding requests that may come from customers of some other business related to the manager -- e.g., no preferential service for customers of a particular data network provider. There can be no requirement that a particular mail system (or other application), protocol, or product be used.

There are no requirements on subdomains beyond the requirements on higher-level domains themselves. That is, the requirements are applied recursively. In particular, all subdomains shall be allowed 
to operate their own domain name servers, providing in them whatever information the subdomain manager sees fit (as long as it is true and correct).

Significantly interested parties in the domain should agree that the designated manager is the appropriate party.

The US Domain Administrator tries to have any contending parties reach agreement among themselves, and generally takes no action to change things unless all the contending parties agree; only in cases where the designated manager has substantially neglected their responsibilities would the US Domain Administrator step in.

The designated manager must do a satisfactory job of operating the DNS service for the domain.

That is, the actual management of the assigning of domain names, delegating subdomains and operating name servers must be done with technical competence. This includes keeping the US Domain Administrator or other higher-level domain managers advised of the status of the domain, responding to requests in a timely manner, and operating the database with accuracy, robustness, and resilience.

There must be a primary and a secondary name server that have IP connectivity to the Internet and can be easily checked for operational status and database accuracy by the US Domain Administrator.

One of the aspects of having two name servers for each domain (or zone), is for robustness. One concern under this heading is that the name service not go out entirely if there is a local power failure (earthquake, tornado, or other disaster).

Name Servers should be in distinctly separate physical locations. It is appropriate to have more than two name servers, but there must be at least two.

For any transfer of the designated manager trusteeship from one organization to another, the higher-level domain manager must receive communications from both the old organization and the new organization that assures the US Domain Administrator that the transfer in mutually agreed, and that the new organization understands its responsibilities.

It is also very helpful for the US Domain Administrator to receive communications from other parties that may be concerned or affected by the transfer. 


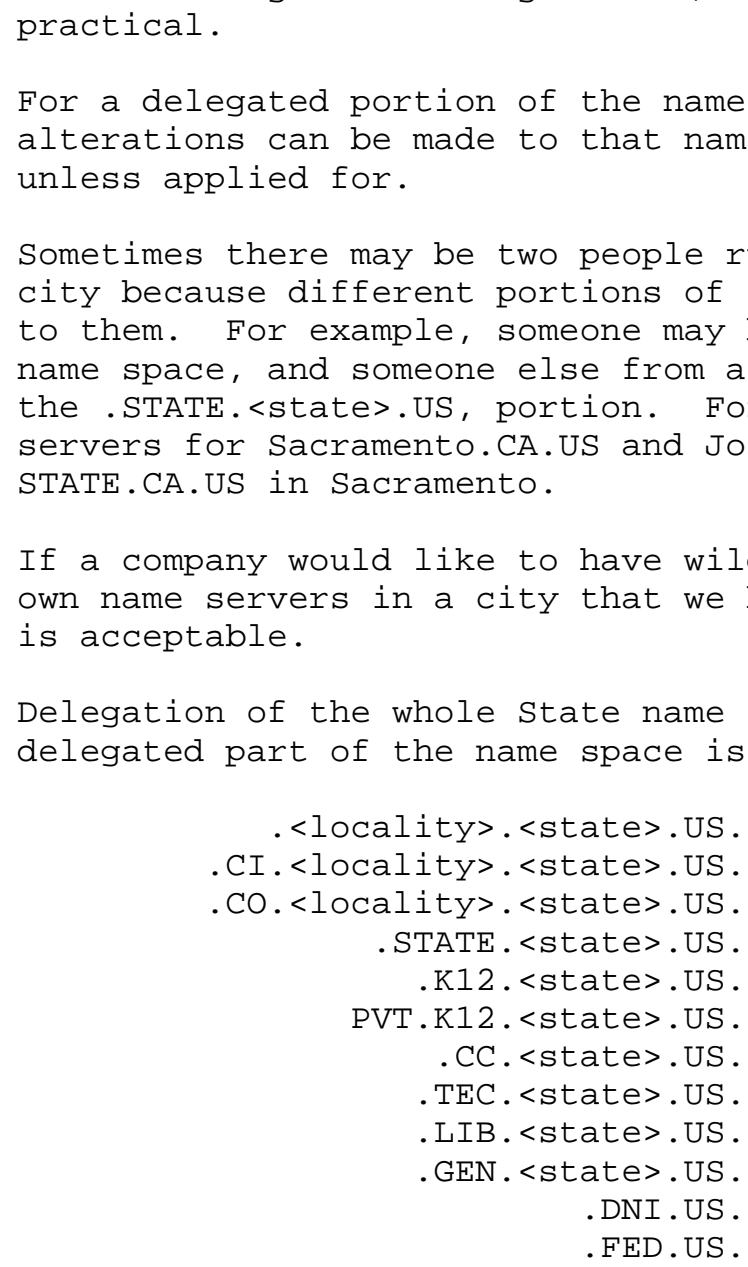

Delegation of the whole state name space is not yet implemented. The delegated part of the name space is in the form of:

3.3.1. Delegation Requirements

When a subdomain is delegated, the following requirements must be met :

1) There must be a knowledgeable and competent technical contact, familiar with the Internet DNS. This requirement is easily satisified if the technical contact already runs some other name servers. 
2) Organizations requesting delegations must provide at least two independent (robust and reliable) DNS name servers in physically separate locations on the Internet.

3) The subdomain must accept all applicants on an equal basis.

4) The subdomain must provide timely processing of requests. To do this, it is helpful to have several individuals knowledgeable about the procedures so that the operations are not delayed due to one persons unavailability (for example, by being on vacation).

5) The subdomain manager must tell the US Domain Administrator when there are changes in the name servers that should be reflected in the US Domain zone files, or changes in the contact information.

\section{K12 Administrators}

In the long term, registering schools will be a big job. So you need to have in mind delegating parts of the work to various school districts. If you can delegate every school district in the state then you are finished, except for checking that they are all operating correctly. However, initially you will have quite a bit to do with educating people, helping them choose names and getting name servers arranged. You are responsible for seeing that the naming of schools follow the guidelines suggested in this memo.

All K12 Administrators will initially be responsible for managing the "pseudo district" PVT for private schools. Private schools have the option of registering as <school-name>.PVT.K12.<state>.US or as a business under the city based names.

Locality Administrators

If you have been delegated a locality subdomain, you will be responsible for registering not only businesses directly under the locality, but city and county agencies under the "CI" and "CO" branches. When appropriate these branches should be delegated.

If you want, you may spell out "CITY" instead of "CI" or "COUNTY" instead of "CO", but you must be consistent and use only one or the other in a given locality. The whole city government should be under one branch. 


\section{WHOIS Database}

Only the second and third level delegated name spaces will be entered in the WHOIS database. For example, K12.CA. US would have an entry in WHOIS. Anything under K12.CA.US will not be listed. The US Domain Administrator will send the information that you supplied on your US Domain template to the InterNIC. It is the hope that in the future, each delegated subdomain will provide their own WHOIS directory database for their branch.

\subsubsection{Delegation Procedures}

The procedure that is followed when a subdomain is delegated includes the following steps:

1) Evaluate the technical contact's experience with DNS. Make sure there is a need for the proposed delegation. Make sure the technical contact has the information about the US Domain and the suggested naming structure. Two contacts with email addresses are necessary in case something goes wrong.

2) Add the new technical contact to the "us-dom-adm" mailing list for distributing updates concerning the US Domain policies and procedures.

3) Delete any hosts from our zone file that belongs in the newly delegated subdomain and make sure they now have the hosts in their zone file.

4) Send them a copy of the zone file so their initial zone file is identical to ours. For example:

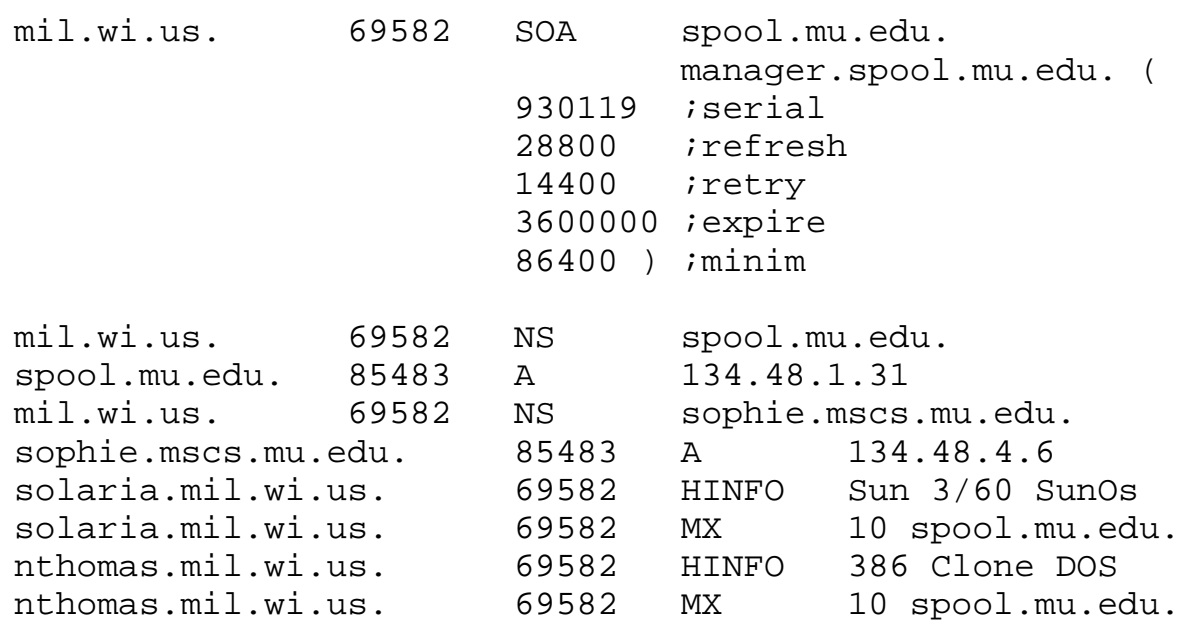




$\begin{array}{llll}\text { rwmke.mil.wi.us. } & 69582 & \text { HINFO } & \text { UNIX PC UNIX } \\ \text { rwmke.mil.wi.us. } & 69582 & \text { MX } & 10 \text { spool.mu.edu. } \\ \text { milestn.mil.wi.us. } & 69582 & \text { MX } & 10 \text { spool.mu.edu. } \\ \text { nrunner.mil.wi.us. } & 69582 & \text { HINFO } & \text { MacIntosh } \text { System 7 } \\ \text { nrunner.mil.wi.us. } & 69582 & \text { MX } & 10 \text { spool.mu.edu. } \\ \text { dawley.mil.wi.us. } & 69582 & \text { HINFO } & 386 \text { Clone Dos } \\ \text { dawley.mil.wi.us. } & 69582 & \text { MX } & 10 \text { spool.mu.edu. }\end{array}$

5) The US Domain zone file must have the following records, showing the name, address, email, and phone number of the technical contact for the delegated subdomain and the name of the delegated name space and the names of the name servers.

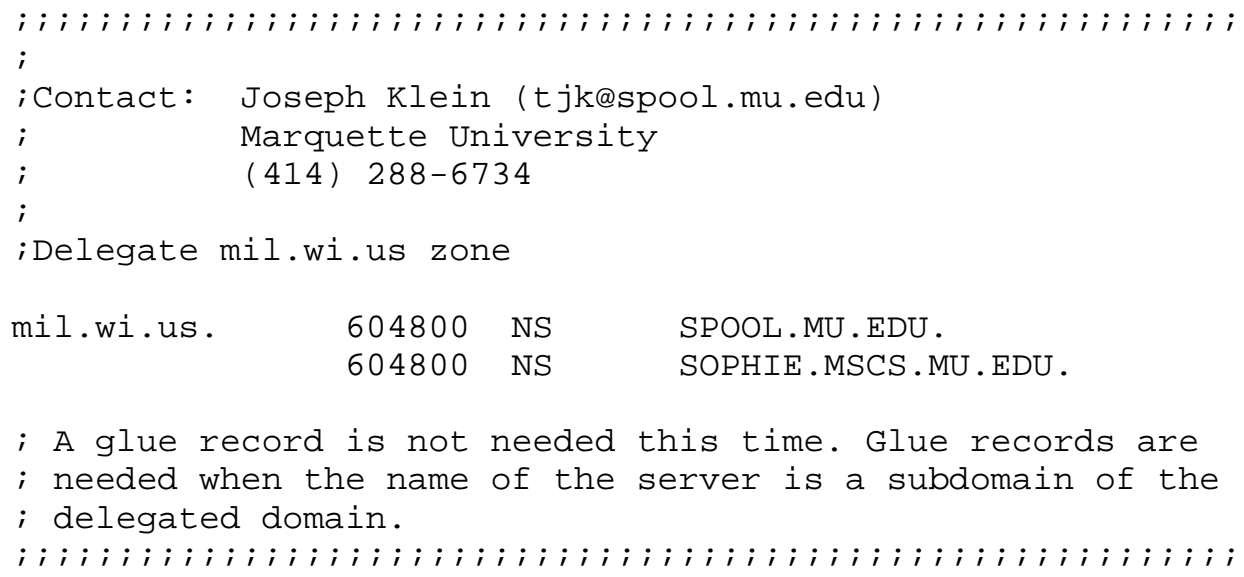

6) Check to see that delegated subdomain name servers are up and running, and make sure the delegated hosts are installed in their zone file. Now delete any hosts from the US Domain zone file that belongs in the newly delegated subdomain.

7) Inform the technical contact of the newly delegated subdomain that wildcard records are allowed in the zone file under the organizational subdomain but no wildcard records are allowed under the "city" or "state" domain.

8) Make sure each administrator has a copy of this RFC and follows the guidelines set forth.

\subsubsection{Subdomain Contacts}

The number of hosts registered under each subdomain is unknown. See Section 3.1 for information on the delegated domains and the contacts. 


\section{DATABASE INFORMATION}

\subsection{Name Servers}

Name servers are the repositories of information that make up the domain database. The database is divided up into sections called zones, which are distributed among the name servers. While name servers can have several optional functions and sources of data, the essential task of a name server is to answer queries using data in its zones. The response to a query can always be generated using only local data, and either contains the answer to the question or a referral to other name servers "closer" to the desired information.

A given zone will be available from several name servers to insure its availability in spite of host or communication link failure. Every zone is required to be available on at least two servers, and many zones have more redundancy than that.

The US Domain is currently supported by seven name servers:

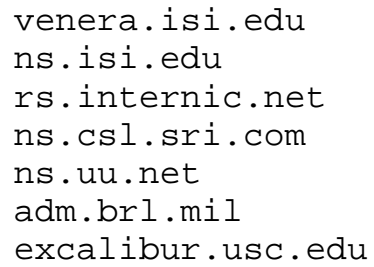

\subsection{Zone Files}

A "zone" is a registry of domains kept by a particular organization. A zone registry is "authoritative", that is, the master copy of the registry is kept by the zone organization, and this copy is, by definition, always up-to-date. Copies of this registry may be distributed to other places and kept in caches, but these caches are not authoritative, and may be out-of-date.

Every zone has at least one node, and hence domain name, for which it is authoritative, and all of the nodes in a particular zone are connected. Given the tree structure, every zone has a highest node which is closer to the root than any other node in the zone. The name of this node is often used to identify the zone. The data that describes a zone has four major parts:

1) Authoritative data for all nodes within the zone.

2) Data that defines the top node of the zone (can be thought of as part of the authoritative data). 
3) Data that describes delegated subzones, i.e., cuts around the bottom of the zone,

4) Data that allows access to name servers for subzones (sometimes called "glue" data).

The zone administrator has to maintain the zones at all the name servers which are authoritative for the zone. When the changes are made, they must be distributed to all of the name servers.

Copies of the zone files are not available unless you are on the Internet. To look at the zone files use the "dig" program of the DNS domain name system.

\section{dig enshost host-your-checking axfr}

\subsection{Resource Records}

Records in the zone data files are called resource records (RRs). The standard Resource records (RR) are specified in STD 13, RFC 1034 and $\operatorname{STD} 13, \operatorname{RFC} 1035(3,4)$. An RR has a standard format as shown.

$$
<\text { name }>[<t \text { l }>\text { ] }[<\text { class }>\text { <type }><\text { data }>
$$

The first field is always the name of the domain record. The second field is an optional time to live field. This specifies how long this data will be stored in the data base. The third field is the address class; the class field specifies the protocol group most often this is the Internet class "IN". The fourth field states the type of the resource record. The fields after that are dependent on the Type of RR. The fifth field is the data field which is defined differently for each type and class of data. Here is a list of the current commonly used types:

$\begin{array}{ll}\text { SOA } & \text { Start of Authority } \\ \text { NS } & \text { Name Server } \\ \text { A } & \text { Internet Address } \\ \text { CNAME } & \text { Canonical Name (nickname pointer) } \\ \text { HINFO } & \text { Host Information } \\ \text { WKS } & \text { Well Known Services } \\ \text { MX } & \text { Mail Exchanger } \\ \text { PTR } & \text { Pointer }\end{array}$


What do the fields mean?

foo.LA.CA.US. 604800 MX $10 \quad$ Venera.ISI.EDU.

(3) (4)

(5)

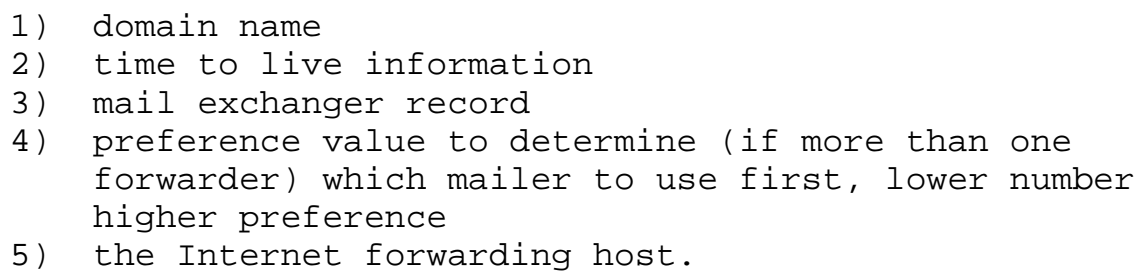

\subsection{1 "A" Records}

Internet (IP) Address. The data for an "A" record is an Internet address in a dotted decimal form. A sample "A" record might look like:
venera.isi.edu.
A $\quad 128.9 .0 .32$
(name)
(A) (address)

The name field is the machine name, and the address is the network address. There should be only one "A" record for each address of a host.

\subsubsection{CNAME Records}

Canonical Name resource record, CNAME, specifies an alias for a canonical name. This is essentially a pointer to the official name for the requested name. All other RRs appear under this official name. A machine named FERNWOOD.MPK.CA.US may want to have the nickname ANTERIOR.MPK.CA.US. In that case, the following RR would be used:

$$
\begin{aligned}
& \text { anterior.mpk.ca.us. CNAME fernwood.mpk.ca.us. } \\
& \text { (alias nickname) (canonical name) }
\end{aligned}
$$

Nicknames (the name associated with the RR is the nickname) may be added for awhile when a host changes its name, usually because it moves to another state. It helps to have this CNAME pointer so if any mail comes to the old address it will get forwarded to the new one. There cannot be any other RRs associated with a nickname of the same class. 


\subsubsection{Records}

Mail Exchanger records, MX, are used to specify a machine that knows how to deliver mail to a machine that is not directly connected to the Internet. For example, venera.isi.edu is the mail gateway that knows how to deliver mail to foo.la.ca.us, but other machines on the network cannot deliver mail directly to foo.la.ca.us. These two machines may have a private connection or use a different transport medium (such as uucp). The preference value (10) is the order that a mailer should follow when there is more than one way to deliver mail to a single machine. The lower the number the higher the preference.

$$
\begin{array}{lllll}
\text { foo.LA.CA.US. } & 604800 & \text { MX } & 10 & \text { Venera.ISI.EDU. } \\
\text { foo.LA.CA.US. } & 604800 & \text { MX } & 20 & \text { relayl.uu.net. }
\end{array}
$$

\subsubsection{HINFO Records}

Host information resource records, HINFO is for host specific data. This lists the hardware and operating system that are running at the listed host. It should be noted that a space separates the hardware information and the operating system information. If you want to include a space in the machine name you must quote the name. Host information is not specific to any class, so ANY may be used for the address class. There should be one HINFO record for each host.

acb.la.ca.us. HINFO VAX-11/780 UNIX

(Hardware) (Operating system)

The official HINFO types can be found in the latest Assigned Numbers RFC, the most recent edition being STD 2, RFC 1340 [9]. The hardware type is called the Machine Name, and the software type is called the System Name.

The information users supply about this is often inconsistent or incomplete. Please follow the terms in the current "Assigned Numbers".

\subsubsection{PTR Records}

A Domain Name Pointer record, PTR, allows special names to point to some other location in the domain data base. These are typically used in setting up reverse pointers for the special IN-ADDR.ARPA domain. PTR names should be unique to the zone.

$$
\begin{aligned}
& \text { 0.0.9.128.in-addr.arpa } \\
& \text { (special name) }
\end{aligned} \quad \text { PTR } \quad \begin{gathered}
\text { isi-net.isi.edu } \\
\text { (real name) }
\end{gathered}
$$


A PTR record is to be added to the IN-ADDR.ARPA domain for every "A" record registered in the US Domain. These PTR records need to be added by the administrator of the network where the host is connected. The US Domain Administration does not administer the network and cannot make these entries in the DNS database.

\subsection{Wildcards}

The wildcard records are of the form "*.<anydomain>", where <anydomain> is any domain name. The wildcards potentially apply to descendents of <anydomain>, but not to <anydomain> itself.

For example, suppose a large company located in California with a large, non-IP/TCP, network wanted to create a mail gateway. If the company was called DWP.LA.CA.US, and the IP/TCP capable gateway machine (Internet forwarder) was called ELROY.JPL.NASA.GOV, the following RRs might be entered into the .US zone.

$\begin{array}{rlll}\text { dwp.la.ca.us } & \text { MX } & 10 & \text { ELROY.JPL.NASA.GOV } \\ \text { *.dwp.la.ca.us } & \text { MX } & 10 & \text { ELROY.JPL.NASA.GOV }\end{array}$

The wildcard record *.DWP.LA.CA.US would cause an MX query for any domain name ending in DWP.LA.CA.US to return an MX RR pointing at ELROY.JPL.NASA.GOV. The entry without the "*" is needed so the host dwp can be found.

In the US Domain, wildcard records are allowed in our zone files under the organizational subdomain (and where noted otherwise) but no wildcard records are allowed under the "City" or "State" domain.

The authors strongly believe that it is in everyone's interest and good for the Internet to have each host explicitly registered (that is, we believe that wildcards should not be used), we also realize that not everyone agrees with this belief. Thus, we will allow wildcard records in the US Domain under groups or organizations. For example, *.DWP.LA.CA.US.

The reason we feel single entries are the best is by the mere fact that if anyone wanted to find one of the hosts in the domain name system it would be there, and problems can be detected more easily. When using wildcards records all the hosts under a subdomain are hidden. 


\section{REFERENCES}

[1] Stahl, M., "Domain Administrators Guide", RFC 1032, SRI International, November 1987.

[2] Lottor, M., "Domain Administrators Operations Guide" RFC 1033, SRI International, November 1987.

[3] Mockapetris, P., "Domain Names - Concepts and Facilities", STD 13, RFC 1034, ISI, November 1987.

[4] Mockapetris, P., "Domain Names - Implementation and Specification", STD 13, RFC 1035, ISI, November 1987.

[5] Dunlap, K., "Name Server Operations Guide for Bind, Release 4.3", UC Berkeley, SMM:11-3.

[6] Partridge, C., "Mail Routing and the Domain Name system", STD 14, RFC 974, BBN, January 1986.

[7] Albitz, P., C. Liu, "DNS and Bind" Help for UNIX System Administrators, O'Reilly and Associates, Inc., October 1992.

[8] ACM SIGUCCS Networking Taskforce, "Connecting to the Internet What Connecting Institutions Should Anticipate", FYI 16, RFC 1359, August 1992.

[9] Reynolds, J., and J. Postel, "Assigned Numbers", STD 2, RFC 1340, ISI, July 1992.

6. Security Considerations

Security issues are not discussed in this memo. 
7. Authors' Addresses

Ann Cooper

USC/Information Sciences Institute

4676 Admiralty Way

Marina del Rey, CA 90292

Phone: 1-310-822-1511

Email: cooperdisi.edu

Jon Postel

USC/Information Sciences Institute 4676 Admiralty Way

Marina del Rey, CA 90292

Phone: 1-310-822-1511

Email: posteldisi.edu 


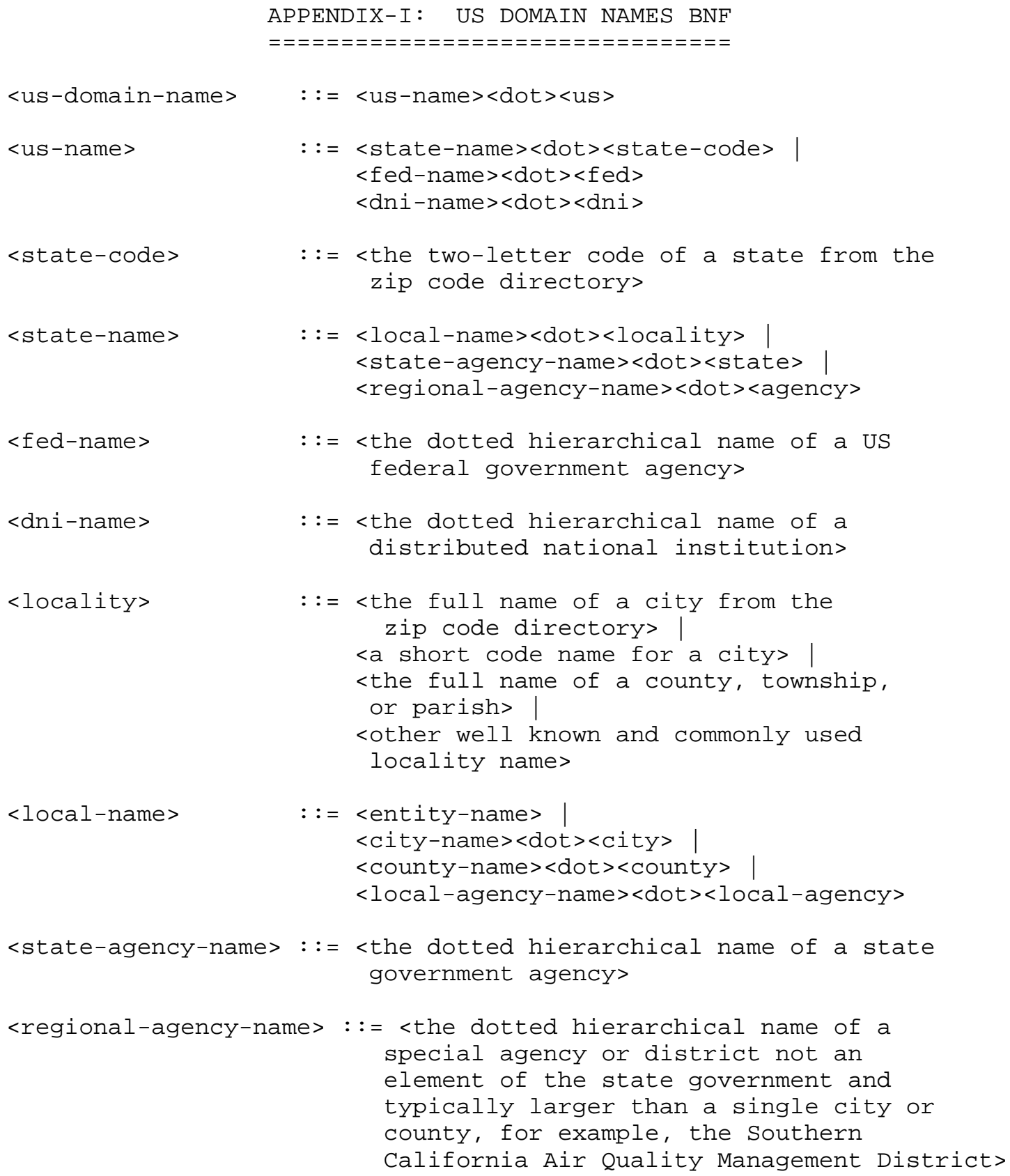




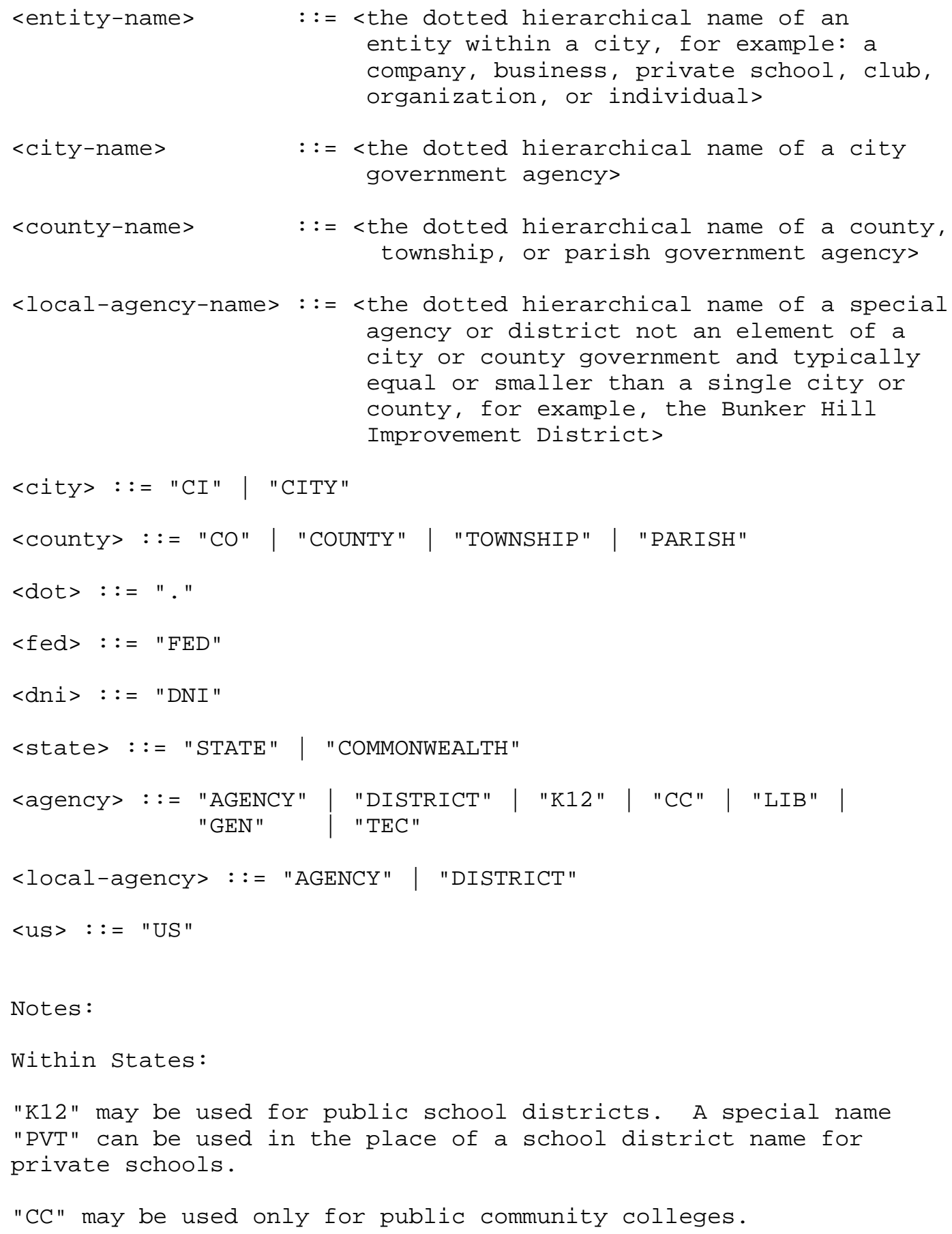




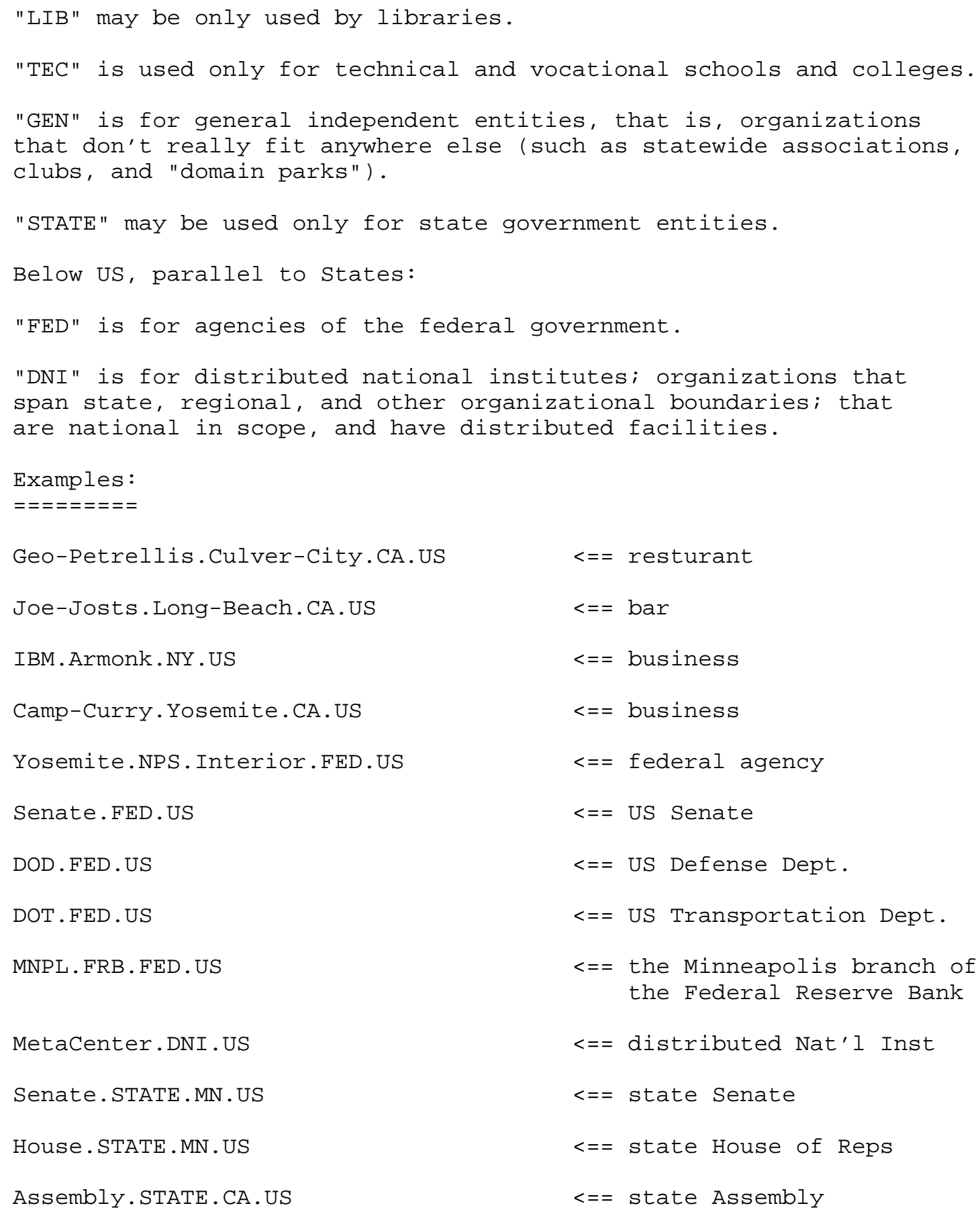




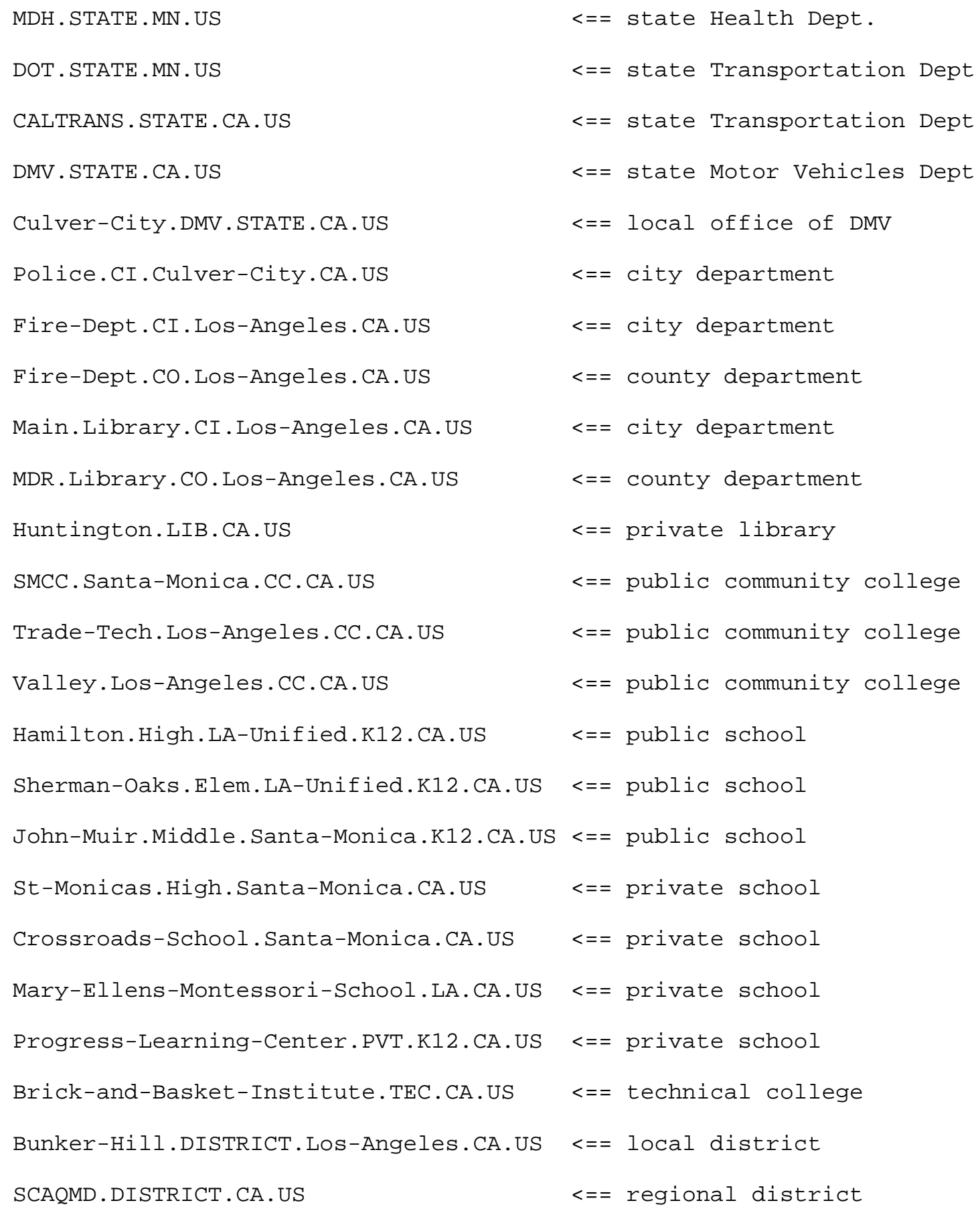




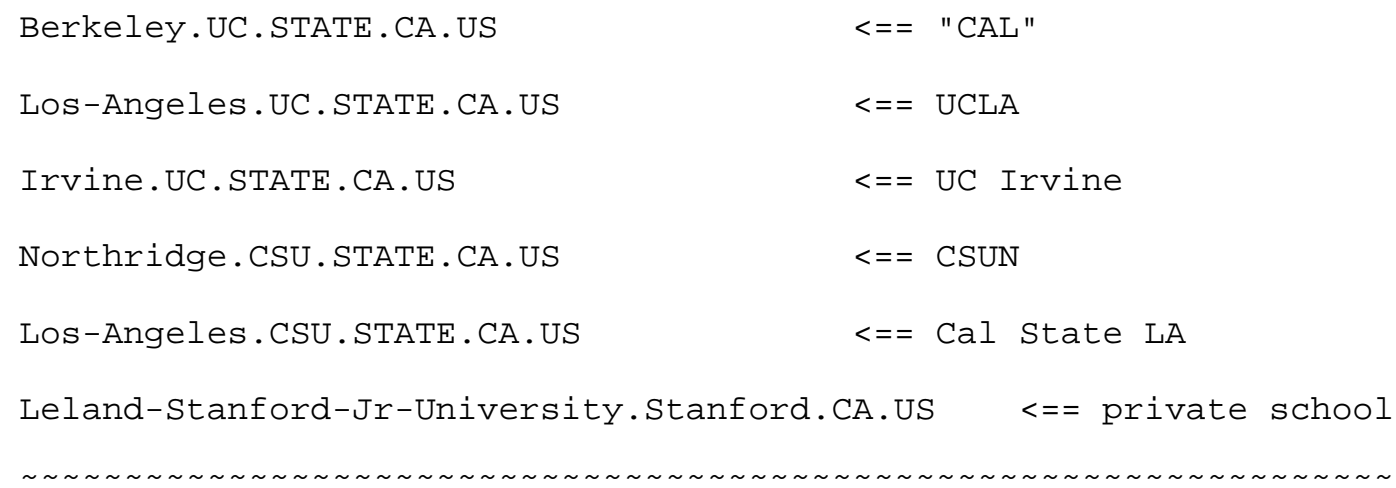


APPENDIX-II: US DOMAIN QUESTIONNAIRE FOR HOST ENTRY

To register a host in the US domain, the US Domain Template must be sent to the US Domain Registrar (US-Domain@ISI.EDU). The first few pages explain each question on the attached template. FILL OUT THE TWO PAGE TEMPLATE AT THE END. Questions may be sent by electronic mail to the above address, or by phone to Ann Cooper, USC/Information Sciences Institute, (310) 822-1511.

(1) Please specify whether this is a new application, modification to an existing registration, or deletion.

(2) The name of the domain. This is the name that will be used in tables and lists associating the domain with the domain server addresses. See RFC 1480 - The US Domain for more details.

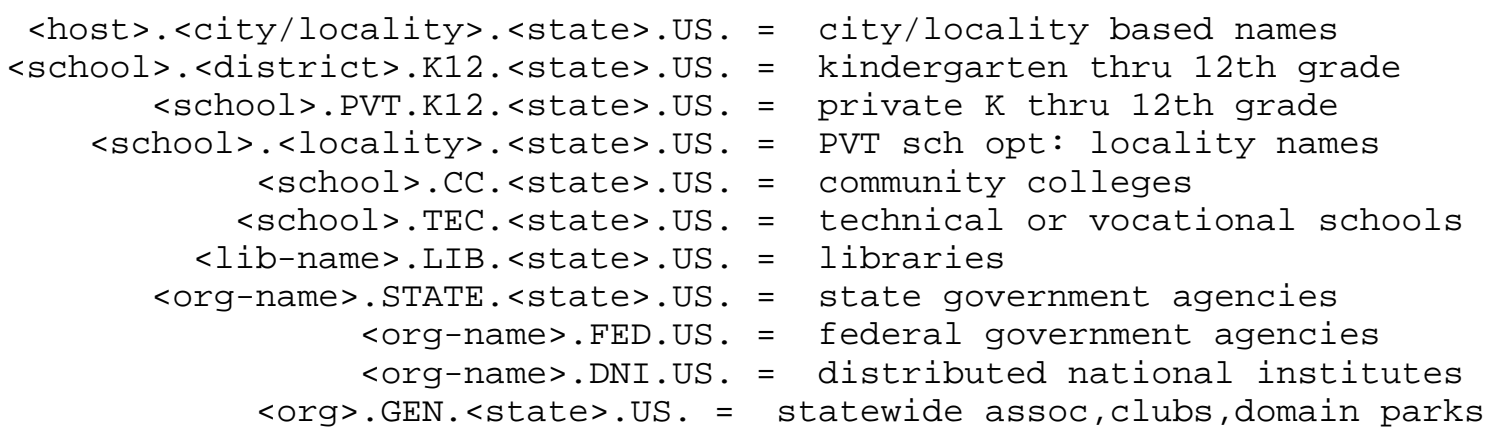

(3) The name of the entity represented, that is, the organization being named. For example: The Networthy Corporation. Not the name of the organization submitting the request.

(4) Please describe the domain briefly.

For example: The Networthy Corporation is a consulting organization of people working with UNIX and the C language in an electronic networking environment. It sponsors two technical conferences annually and distributes a bimonthly newsletter.

(5) The date you expect the domain to be fully operational. 
For every registration, we need both the Administrative and the Technical contacts of a domain (questions 6 \& 7) and we MUST have a network mailbox for each. If you have a NIC handle (a unique NIC database identifier) please enter it. (If you don't know what a NIC handle is leave it blank). Also the title, mailing address, phone number, organization, and network mailbox.

(6) The name of the administrative head of the "organization". The administrator is the contact point for administrative and policy questions about the domain. The Domain administrator should work closely with the personnel he has designated as the "technical contact" for his domain. In this example the Domain Administrator would be the Administrator of the Networthy Corporation, not the Administrator of the organization running the name server (unless it is the same person).

(7) The name of the technical and zone contact. The technical and zone contact handles the technical aspects of maintaining the domain's name server and resolver software, and database files. He keeps the name server running. More than likely, this person would be the technical contact running the primary name server.

PLEASE READ: There are several types of registrations.

(a) Delegation (i.e., a portion of the US Domain name space is given to an organization running name servers to support that branch; For example, K12.TX.US, for all K12 schools in Texas). For (a) answer questions 8 and 9.

(b) Direct Registration of an IP Host. For (b) answer question 10.

(c) Direct Registration of a non-IP Host. For (c) answer question 11 and 12 .

\section{QUESTIONS FOR DELEGATIONS}

(8) PRIMARY SERVER Information. It is required to supply both the Contact information as well as hardware/software information of the primary name server.

(9) * SECONDARY SERVER Information. It is required to supply the hardware and software information of all secondary name servers. 
Domains must provide at least two independent servers that provide the domain service for translating names to addresses for hosts in this domain. If you are applying for a domain and a network number assignment simultaneously and a host on your proposed network will be used as a server for the domain, you must wait until you receive your network number assignment and have given the server(s) a net- address before sending in the domain application. Establishing the servers in physically separate locations and on different PSNs and/or networks is strongly recommended.

NOTE: For those applicants not able to run name servers, or for non-IP hosts the Name Server information is not applicable. (See \#10 and \#11).

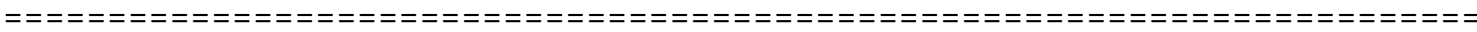
QUESTION FOR DIRECT IP HOSTS (If you answered 8 \& 9 do not answer 10,11 , or 12).

(10) What Domain Name System (DNS) Resource Records (RR) and values are to be entered for your IP host (must have an "A" record).

$++++++++++++++++++++++++++++++++++++++++++++++++++++++++++++++++++$ Example: RRs for an INTERNET hosts.

(a) DOMAIN NAME (required)...: Networthy.Santa-Clara.CA.US.

(b) IP ADDRESS (required)....: A 128.9.3.123 (required)

(c) HARDWARE (opt) ......... S SUN-3/110

(d) OPERATING SYS (opt) .....: UNIX

(e) WKS (opt)....... 128.9.3.123. UDP (echo tftp) TCP (ftp)

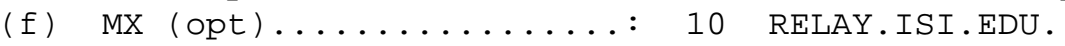

It is your responsibility to see that an IN-ADDR pointer record is entered in the DNS database. (For Internet hosts only). Contact the administrator of the IP network your host is on to have this done. The US Domain administration does not administer the network and cannot make these entries in the DNS database.

QUESTIONS FOR NON-IP HOSTS (such as UUCP).

Many applicants have hosts in the UUCP world. Some are one hop away, some two and three hops away from their "Internet Forwarder", this is ok. What is important is getting an Internet host to be your forwarder. If you do not already have an Internet forwarder, there are several businesses that provide this service for a fee, (see RFC 1359 - Connecting to the Internet what Connecting Institutions Should Anticipate, ACM SIGUCCS, August 1992). Sometimes local colleges in your area are already on the Internet and may be willing to act as an Internet Forwarder. You would need to work this out with the systems administrator. We cannot make these arrangements for you. 
(11) Internet Forwarding Host Information

(11a) What is the name of your Internet forwarding host?

For example: The host Yacht-Club.MDR.CA.US uses UUCP to connect to RELAY.ISI.EDU which is an Internet host. (i.e., RELAY.ISI.EDU is the forwarding host).

(11b) What is the name of your contact person at forwarding host? The Administrator of RELAY.ISI.EDU must agree to be the forwarding host for Yacht-Club.MDR.CA.US, and the forwarding host must know a delivery method and route to Networthy. No double MXing.

(11c) What is the mailbox of your contact? What is the mailbox of the administrator of the forwarding host.

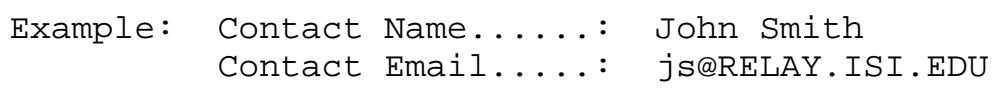

(12) What Domain Name System (DNS) Resource Records (RR) and values are to be entered for your NON-IP host.

$++++++++++++++++++++++++++++++++++++++++++++++++++++++++++++++++++$ Example: RRs for a NON-IP host (uucp).
(a) DOMAIN NAME (required)....: : Yacht-Club.MDR.CA.US .
(b) HARDWARE (opt) ........... S SUN-3/110
(c) OPERATING SYS (opt) ....... UN UNIX
(d) $\mathrm{MX}$ (required)........... 10 RELAY.ISI.EDU.
$++++++++++++++++++++++++++++++++++++++++++++++++++++++++++++++++++$

PLEASE ALLOW AT LEAST 8 WORKING DAYS FOR PROCESSING THIS APPLICATION 
PLEASE SUBMIT THE FOLLOWING TWO PAGE TEMPLATE TO (Us-Domain@isi.edu). Sections or fields of this form marked with an asterisk (*) may be copied as many times as necessary. (For example: If you had two phone numbers for the Administrative Contact, you would use the same number "6h" twice. PLEASE DO NOT ALTER THIS APPLICATION IN ANY WAY.

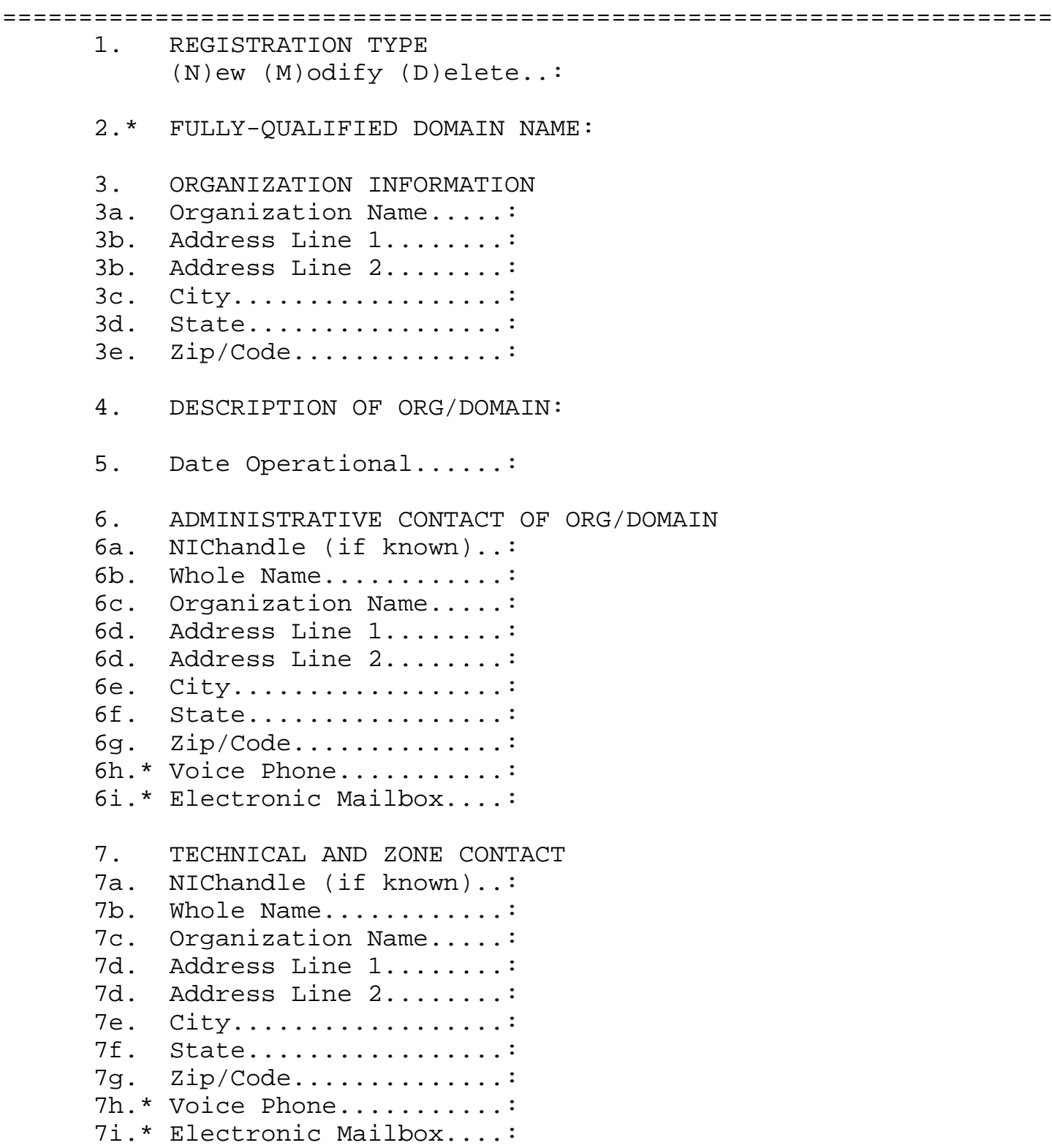


FILL OUT QUESTIONS 8 AND 9 FOR DELEGATIONS ONLY (i.e., those organizations running name servers for a branch of the US Domain name space, for example: $\mathrm{k} 12$. <state>.us).

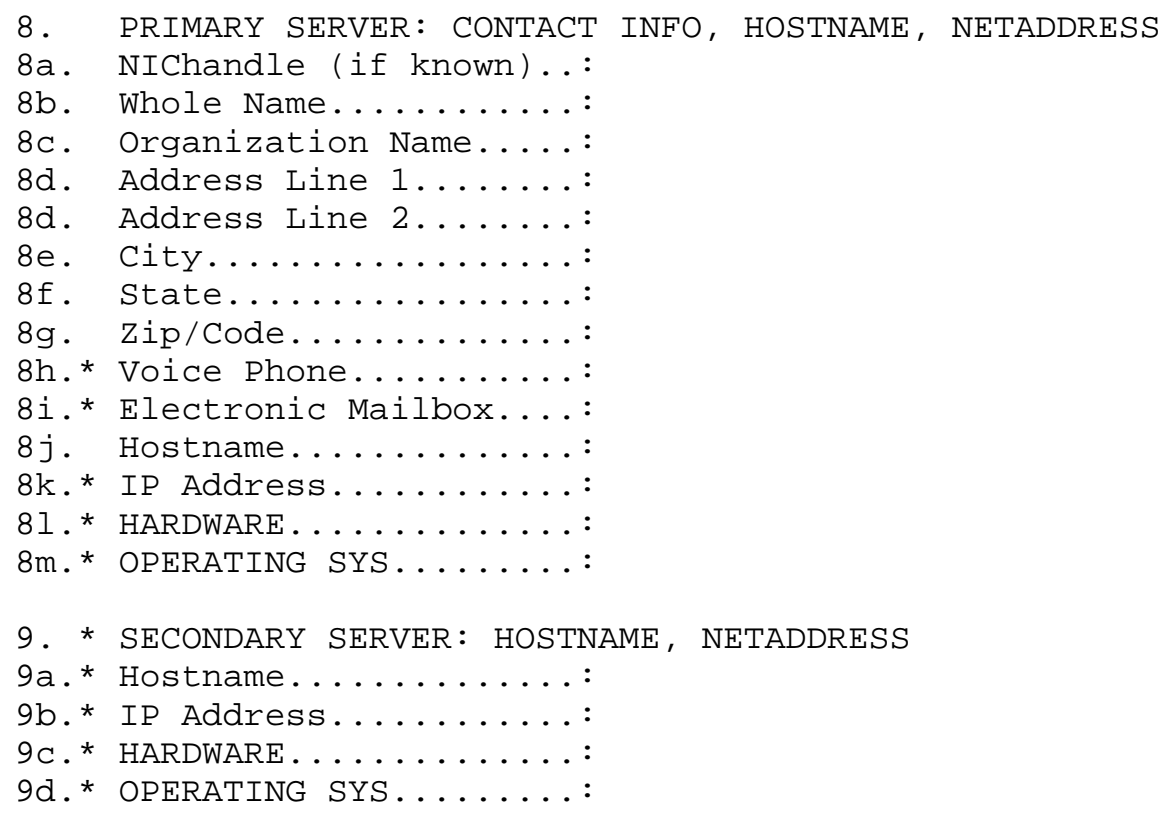

FILL OUT QUESTION 10 FOR DIRECT REGISTRATIONS IP HOSTS

10. RESOURCE RECORDS (RRS) FOR IP INTERNET HOSTS

10a. DOMAIN NAME.........

10b.* IP ADDRESS (required).:

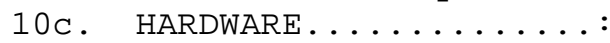

10d. OPERATING SYS........

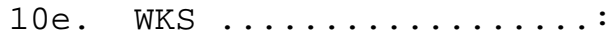

$10 \mathrm{f} . \star \mathrm{MX} . \ldots \ldots \ldots \ldots$

FILL OUT QUESTIONS 11 AND 12 FOR NON-IP HOSTS (such as UUCP)

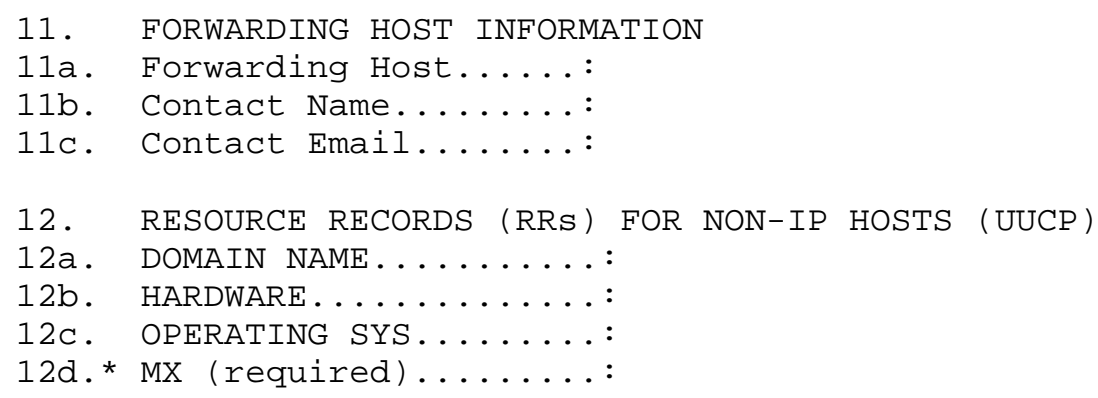

